\title{
Cortical Action Potential Backpropagation Explains Spike Threshold Variability and Rapid-Onset Kinetics
}

\author{
Yuguo Yu, ${ }^{1}$ Yousheng Shu, ${ }^{2}$ and David A. McCormick ${ }^{1}$ \\ ${ }^{1}$ Department of Neurobiology, Kavli Institute of Neuroscience, Yale University School of Medicine, New Haven, Connecticut 06510, and ${ }^{2}$ Institute of \\ Neuroscience and State Key Laboratory of Neuroscience, Shanghai Institutes for Biological Sciences, Chinese Academy of Sciences, Shanghai 200031, China
}

\begin{abstract}
Neocortical action potential responses in vivo are characterized by considerable threshold variability, and thus timing and rate variability, even under seemingly identical conditions. This finding suggests that cortical ensembles are required for accurate sensorimotor integration and processing. Intracellularly, trial-to-trial variability results not only from variation in synaptic activities, but also in the transformation of these into patterns of action potentials. Through simultaneous axonal and somatic recordings and computational simulations, we demonstrate that the initiation of action potentials in the axon initial segment followed by backpropagation of these spikes throughout the neuron results in a distortion of the relationship between the timing of synaptic and action potential events. In addition, this backpropagation also results in an unusually high rate of rise of membrane potential at the foot of the action potential. The distortion of the relationship between the amplitude time course of synaptic inputs and action potential output caused by spike backpropagation results in the appearance of high spike threshold variability at the level of the soma. At the point of spike initiation, the axon initial segment, threshold variability is considerably less. Our results indicate that spike generation in cortical neurons is largely as expected by Hodgkin-Huxley theory and is more precise than previously thought.
\end{abstract}

Key words: axon; kink; Hodgkin-Huxley; pyramidal cell; spike timing; $\mathrm{Na}^{+}$channels

\section{Introduction}

The transmission of information within the brain depends critically on the transformation of synaptic barrages into patterns of action potentials and, through synaptic transmission, back into synaptic activity. A critical feature of this underlying property of information processing is, therefore, the precise basis of the synaptic barrage-action potential transfer function. Intracellular recordings in vitro suggest that cortical neurons can respond with great temporal precision to the repeated injection of complex synaptic-barrage-like waveforms, as long as these waveforms contain higher-frequency components (Mainen and Sejnowski, 1995; Nowak et al., 1997). Intrasomatic in vivo recordings, however, reveal a noisy relationship between membrane potential and action potential firing threshold (Azouz and Gray, 1999, 2000; Anderson et al., 2000; Henze and Buzsaki, 2001). Previous studies have hypothesized that a significant portion of this noisy relationship is caused by a rough correlation between the rate of rise of prespike membrane potential and action potential threshold (Azouz and Gray, 1999, 2000, 2003; Henze and Buzsaki, 2001) and a dependence of spike threshold on the recent history of action potential activity (Henze and Buzsaki, 2001; Shu et al., 2003). However, these two factors alone explain only a portion

\footnotetext{
Received April 14, 2008; revised May 16, 2008; accepted June 2, 2008.

This work was supported by the National Institutes of Health. We thank Flavio Frohlich for comments on this manuscript.

Correspondence should be addressed to David A. McCormick, Department of Neurobiology, Kavli Institute of Neuroscience, Yale University School of Medicine, 333 Cedar Street, New Haven, CT 06510. E-mail: david.mccormick@yale.edu.

DOI:10.1523/JNEUROSCI.1613-08.2008

Copyright $\odot 2008$ Society for Neuroscience $\quad$ 0270-6474/08/287260-13\$15.00/0
}

( $\sim 40-60 \%)$ of spike threshold variance. Recently, it was suggested that high spike threshold variance may result from cooperative gating of $\mathrm{Na}^{+}$channels in cortical pyramidal cells, resulting in a tendency for nearby $\mathrm{Na}^{+}$channels to rapidly open and close together, endowing action potentials with an usually rapid ("kinky") onset and high spike threshold variability (Naundorf et al., 2006). If true, this interchannel cooperativity would form a radical new mechanism by which voltage-dependent ionic channels may function (Gutkin and Ermentrout, 2006), and would overturn long held assumptions of channel independence that have been central to models of action potential generation dating back to the landmark study of Hodgkin and Huxley (1952).

An important caveat in the study of spike threshold variance and the properties of spike initiation for cortical cells is the fact that intracellular recordings in vivo are obtained from the cell body/and or proximal dendrite, although action potentials initiate at a distance, in the axon initial segment (AIS) (Stuart et al., 1997a; Palmer and Stuart, 2006; Shu et al., 2007b). We commented previously that this arrangement of action potential generation and propagation may result in apparent high spike threshold variability, even when the true variability at the site of spike initiation is relatively low (McCormick et al., 2007). Here, we fully demonstrate with simultaneous axonal and somatic patch-clamp recordings together with Hodgkin-Huxley $(\mathrm{HH})$ style models that a large portion of somatic spike threshold variability arises from the active backpropagation of action potentials from the axon and that actual threshold variance is relatively low, as predicted by $\mathrm{HH}$ theory. This finding has important implications for our understanding of information processing in cortical networks. 


\section{Materials and Methods}

Experiments were performed on slices of ferret (7-10 weeks old) prefrontal and somatosensory cortex maintained in vitro in a submerged-style recording chamber at $36.5^{\circ} \mathrm{C}$. The ACSF contained (in mM) $126 \mathrm{NaCl}, 2.5$ $\mathrm{KCl}, 2 \mathrm{MgSO}_{4}, 2 \mathrm{CaCl}_{2}, 26 \mathrm{NaHCO}_{3}, 1.25 \mathrm{NaH}_{2} \mathrm{PO}_{4}$, and 25 dextrose, $315 \mathrm{mOsm}, \mathrm{pH}$ 7.4. Recordings were done on an upright infrareddifferential interference contrast microscope (Zeiss Axioskop 2 FS plus). The membrane potentials in our whole-cell recordings were corrected for Donnan liquid junction potentials of $10 \mathrm{mV}$ (Neher, 1992; Fricker et al., 1999).

Whole-cell recordings were achieved from both the soma and the cut end of the main axon using a Multiclamp 700B amplifier (Molecular Devices) as described previously (Shu et al., 2006, 2007a,b). Pipettes had impedances of 5-6 and 9-15 M $\Omega$ for somatic and axonal recordings, respectively, and were filled with an intracellular solution that contained (in mM) $140 \mathrm{~K}$ gluconate, $3 \mathrm{KCl}, 2 \mathrm{MgCl}_{2}, 2 \mathrm{Na}_{2} \mathrm{ATP}, 10$ HEPES, and 0.2 EGTA, pH 7.2 with $\mathrm{KOH}(288 \mathrm{mOsm})$. Alexa Fluor $488(100 \mu \mathrm{M})$ and biocytin $(0.2 \%)$ were added to the pipette solution for tracing and labeling the recorded pyramidal cells.

Unless otherwise stated, data were collected at 33-66 kHz in Spike2 (Cambridge Electronic Design) and Matlab (MathWorks). All error bars were calculated as the SEM and data in the text are reported as mean \pm SD. The criterion for spike threshold was set at between 15 and $20 \mathrm{~V} / \mathrm{s}$ because this is just above the maximal level of $d V / d t$ obtained by our noise injection when action potentials were not initiated. Fixing the threshold at higher or lower levels near this criterion value did not alter the basic results. A number of experiments were performed with a dynamic clamp as described previously (Shu et al., 2003). Noisy mixed excitatory and inhibitory conductances were constructed according to an Ornstein-Uhlenbeck (colored noise) model (Destexhe et al., 2001).

\section{Excitatory and inhibitory synaptic noise}

A point-conductance model was generated to approximate synaptic background activity. The total synaptic current, $I_{\text {syn }}$, was decomposed into a sum of two independent conductances: $I_{\text {syn }}=g_{e}(t)\left(V-E_{e}\right)+$ $g_{i}(t)\left(V-E_{i}\right)$, where $g_{e}(t)$ and $g_{i}(t)$ are time-dependent excitatory and inhibitory conductances, respectively, and $E_{e}=0 \mathrm{mV}$ and $E_{i}=-75 \mathrm{mV}$ are their respective reversal potentials. The conductances $g_{e}(t)$ and $g_{i}(t)$ were described by a one-variable stochastic process similar to the Ornstein-Uhlenbeck process:

$$
\begin{gathered}
\frac{d g_{e}(t)}{d t}=-\frac{1}{\tau_{e}}\left[g_{e}(t)-g_{e 0}\right]+\sqrt{D_{e}} \lambda_{e}(t) \\
\frac{d g_{i}(t)}{d t}=-\frac{1}{\tau_{i}}\left[g_{i}(t)-g_{i 0}\right]+\sqrt{D_{i}} \lambda_{i}(t)
\end{gathered}
$$

where $g_{e 0}(0.0121 \mu \mathrm{S})$ and $g_{i 0}(0.0573 \mu \mathrm{S})$ are average conductances, $\tau_{e}$ $(2.7 \mathrm{~ms})$ and $\tau_{i}(10.5 \mathrm{~ms})$ are time constants, $\lambda_{1}(t)$ and $\lambda_{2}(t)$ are Gaussian white-noise controlled, respectively, by zero mean and SD $\xi_{e}(0.006 \mu \mathrm{S})$ and $\xi_{i}(0.012 \mu \mathrm{S}) . D_{e}$ and $D_{i}$ are noise diffusion coefficients, which are given by $D_{e}=2 \xi_{e}^{2} / \tau_{e}$ and $D_{i}=2 \xi_{i}^{2} / \tau_{i}$, respectively.

\section{Methods for computational model of action potential generation in cortical neurons}

We first modeled the initiation and propagation of action potentials in simple models of axons. These models consisted of a cylindrical tube, initially $2000 \mu \mathrm{m}$ in length (see Figs. 2, 5). To examine the effects of action potential conduction into areas of spatial nonuniformity, such as into a soma and/or dendrite, we added simple somatic and dendritic compartments. To demonstrate that the results we obtained with our simple models are applicable to more realistic model neurons, we used the models of Mainen and Sejnowski (Mainen et al., 1995; Mainen and Sejnowski, 1996) and Hoffman et al. (1997), Migliore et al. (1999), and Poolos et al. (2002). Our models were implemented in NEURON (Hines and Carnevale, 1997) at a temperature of $37^{\circ} \mathrm{C}$. For the simple models, only Hodgkin-Huxley-style $\mathrm{Na}^{+}$and $\mathrm{K}^{+}$conductances were included, along with a linear leak current. The following equations describing the voltage and time dependence of the $\mathrm{Na}^{+}$and $\mathrm{K}^{+}$conductances were from the studies by Mainen et al. (1995) and Mainen and Sejnowski (1996), which are based on previous publications (McCormick and Huguenard, 1992): $I_{\mathrm{Na}}$ $=g_{\mathrm{Na}} m^{3} h\left(V-E_{\mathrm{Na}}\right) ; I_{k}=g_{k} n\left(V-E_{k}\right) ; I_{l}=g_{l}\left(V-E_{l}\right)$.

The simplest model is that in Figures 2 and 5, which consists of a uniform cylindrical axon (2000 $\mu \mathrm{m}$ length, $1 \mu \mathrm{m}$ diameter, 400 compartments) in which the internal resistance, $R_{2}$, is $150 \Omega \cdot \mathrm{cm}$ and the specific membrane capacitance is $0.75 \mu \mathrm{F} / \mathrm{cm}^{2}$. The density of $g_{\mathrm{Na}}$ is $8000 \mathrm{pS} /$ $\mu \mathrm{m}^{2}$, whereas the density of $g_{\mathrm{K}}$ is $1500 \mathrm{pS} / \mu \mathrm{m}^{2}$ and $g_{\text {leak }}$ is $0.33 \mathrm{pS} / \mu \mathrm{m}^{2}$. The beginning and ends of the axon are modeled as sealed. These values of $g_{\mathrm{Na}}$ were used to match those of the full neuron model (see Fig. 8), although they yield peak $d V / d t$ rates that are significantly higher than those seen in real neurons. Lowering the $g_{\mathrm{Na}}$ such that the peak $d V / d t$ rates were comparable with those of layer 5 pyramidal cells in vitro yielded results similar to those illustrated here (data not shown).

In Figures 3 and 7, the model axon was reduced in length to 50-80 $\mu \mathrm{m}$. In Figures $3 a-d$ and $7 a$, the axon was $80 \mu \mathrm{m}$ long (16 compartments) with the same properties as in Figure 2. In Figures $3 e-h$ and $7 b$, the first $30 \mu \mathrm{m}$ of axon was replaced with a soma that was $20 \mu \mathrm{m}$ in diameter (six compartments) that had a density of $g_{\mathrm{Na}}=800 \mathrm{pS} / \mu \mathrm{m}^{2}$ and $g_{\mathrm{K}}=320 \mathrm{pS} / \mu \mathrm{m}^{2}$. In Figures $3 i-l$ and $7 c$, a single dendrite of 3000 $\mu \mathrm{m}$ length and $5 \mu \mathrm{m}$ diameter (60 compartments) was attached to the soma. The dendrite contained a low density of $g_{\mathrm{Na}}\left(20 \mathrm{pS} / \mu \mathrm{m}^{2}\right)$ and $g_{\mathrm{K}}$ $\left(10 \mathrm{pS} / \mu \mathrm{m}^{2}\right)$. The dendrite provided a conductance load of $8.4 \mathrm{nS}$ and a capacitive load of $78 \mathrm{pF}$ to the soma, which are conservative values because the fully reconstructed dendritic arbor of a layer 5 pyramidal cell (Fig. 8) added $21.5 \mathrm{nS}$ and $375 \mathrm{pS}$.

\section{Detailed methods of cortical cell model: higher $\mathrm{Na}^{+}$conductance in axon initial segment model}

Cortical neurons initiate action potentials in their axon initial segments under a wide variety of conditions. These action potentials then propagate antidromically (backpropagate) through the soma and to variable degrees into the dendritic arbor (Stuart et al., 1997b; Palmer and Stuart, 2006; Shu et al., 2007b). There are two different hypothesis concerning spike initiation: one based on a high density of $\mathrm{Na}^{+}$channels in the axon initial segment (Mainen et al., 1995; Mainen and Sejnowski, 1996; Komada and Soriano, 2002; Inda et al., 2006) and another based on a modest density of $\mathrm{Na}^{+}$channels that have a more negative threshold than those in the soma (Colbert and Johnston, 1996; Colbert and Pan, 2002). The precise density of $\mathrm{Na}^{+}$channels in the axon initial segment is unknown. Here, we used an empirical approach to approximate the density of $\mathrm{Na}^{+}$channels for our full neuron model (see below). We measured the $d V / d t$ of the membrane potential in the axon initial segment in real neurons and adjusted the concentration of $\mathrm{Na}^{+}$and $\mathrm{K}^{+}$currents in the axon initial segment of our model to match these empirically determined values. Using this method, we formed a model that initiates action potentials at $\sim 45 \mu \mathrm{m}$ from the cell body (as we have observed in real neurons) (Shu et al., 2007a,b), and which gave rise to $d V / d t$ plots for spike initiation that were similar to those recorded in real neurons (e.g., a peak $d V / d t$ of $\sim 1200 \mathrm{mV} / \mathrm{ms}$ at the axon initial segment was used as a conservative value) (Kole et al., 2007) (supplemental Fig. 1, available at www. jneurosci.org as supplemental material). It should be noted that cutting and artificially sealing the end of the main axon results in an $\sim 15-20 \%$ increase in the peak $d V / d t$ at the end of the cut axon (Kole et al., 2007) (supplemental Fig. 2, available at www.jneurosci.org as supplemental material).

Our full computational model is based on the published multicompartmental model of the full dendritic and somatic structure of a layer 5 cortical pyramidal cell [Mainen and Sejnowki (1996), their Fig. $1 D$ ]. The temperature of the modeled cell was $37^{\circ} \mathrm{C}$.

Dendrites and soma. The soma and dendrites contain 440 compartments. The somatic surface area is $2748 \mu \mathrm{m}^{2}$, its diameter is $25 \mu \mathrm{m}$, and its length is $35 \mu \mathrm{m}$. There are 11 primary neurites and 87 branches, totaling $17,668 \mu \mathrm{m}$ in length and 78,858 $\mu \mathrm{m}^{2}$ in surface area.

Axon. Our model of the axon was based on that of Mainen et al. (1995) and was modified to match the spike initiation properties of our layer 5 pyramidal cells. The soma connects to the axon hillock, which tapers from 4.8 to $1.2 \mu \mathrm{m}$ and has a length of $10 \mu \mathrm{m}$. The hillock is followed by a $40 \mu \mathrm{m}$ initial segment of $1.2 \mu \mathrm{m}$ diameter. Following the initial seg- 
ment, there is a myelinated axon $500 \mu \mathrm{m}$ in length, with internode distances of $100 \mu \mathrm{m}$. The diameter of the internode axon is $1.22 \mu \mathrm{m}$ and the node diameter $0.91 \mu \mathrm{m}$ with a length of $1 \mu \mathrm{m}$.

Electrical properties. The membrane capacitance $\left(C_{\mathrm{m}}\right)$ for the soma, dendrites, and unmyelinated axon is modeled as $0.75 \mu \mathrm{F} / \mathrm{cm}^{2}$, whereas for the myelinated axon, it is modeled as $0.04 \mu \mathrm{F} / \mathrm{cm}^{2}$. The axial resistance for the dendrites and axons is $150 \Omega \cdot \mathrm{cm}$ (Mainen and Sejnowski, 1996). The membrane time constant of the soma, dendrites, hillock, and initial segment is $\sim 28 \mathrm{~ms}$, whereas it is $1.5 \mathrm{~ms}$ for the myelinated axon and $0.5 \mathrm{~ms}$ for nodes.

Channel distributions. The transient $\mathrm{Na}^{+}$current is present in all parts of the modeled cell and its density is moderately high in the initial segment and hillock $\left(8000 \mathrm{pS} / \mu \mathrm{m}^{2}\right)$, but low in the soma $\left(750 \mathrm{pS} / \mu \mathrm{m}^{2}\right)$ and dendrites $\left(100 \mathrm{pS} / \mu \mathrm{m}^{2}\right)$. The myelinated model axon has a $\mathrm{Na}^{+}$conductance of $20 \mathrm{pS} / \mu \mathrm{m}^{2}$ for internodal regions and $5000 \mathrm{pS} / \mu \mathrm{m}^{2}$ for each node. The reversal potential of $\mathrm{Na}^{+}$in this model is $60 \mathrm{mV}$. The fast, voltage-activated $\mathrm{K}^{+}$current, $I_{\mathrm{Kv}}$, is present only in the model hillock, initial segment $\left(800 \mathrm{pS} / \mu \mathrm{m}^{2}\right)$, and soma $\left(80 \mathrm{pS} / \mu \mathrm{m}^{2}\right)$. The reversal potential of $\mathrm{K}^{+}$is $-90 \mathrm{mV}$. Background leak current is distributed throughout the cell. In the soma, dendrites, hillock, initial segments, and unmyelinated axon, $g_{\text {leak }}=0.333 \mathrm{pS} / \mu \mathrm{m}^{2}$. In the nodes, $g_{\text {leak }}=200$ $\mathrm{pS} / \mu \mathrm{m}^{2}$. The reversal potential of the leak current is $-70 \mathrm{mV}$. The slow noninactivating potassium current $\left(\mathrm{M}\right.$ current; $\left.I_{\mathrm{KM}}\right)$, high-voltageactivated $\mathrm{Ca}^{2+}$ current, $I_{\mathrm{Ca}}$, and one $\mathrm{Ca}^{2+}$-dependent $\mathrm{K}^{+}$current, $I_{\mathrm{KCa}}$, are distributed throughout the soma and dendrites $\left(K_{\mathrm{M}}\right.$ conductance, 0.1 ; Ca conductance, 0.3 ; and $K_{\mathrm{Ca}}$ conductance, $3 \mathrm{pS} / \mu \mathrm{m}^{2}$ ) as per Mainen and Sejnowski (1996). The reversal potential of Ca is $140 \mathrm{mV}$. For the specific rate functions for the different ionic channels, please see Mainen and Sejnowski (1996).

\section{Spike initiation based on lower threshold for $\mathrm{Na}^{+}$current in the} axon initial segment

In addition to the modified model of Mainen and Sejnowski (1996), we also verified our results with another full model based on a moderate density of $\mathrm{Na}^{+}$channels, with a lower threshold for activation, in the axon initial segment (Migliore et al., 1999; Colbert and Pan, 2002; Poolos et al., 2002). In this model by Colbert, Migliore, and Johnston, the authors set sodium density in the axon initial segment at only two or three times larger than that in cell body and dendrites. Action potentials initiate $\sim 30 \mu \mathrm{m}$ from the cell body. Details of the model can be obtained from the studies by Migliore et al. (1999), Colbert and Pan (2002), and Poolos et al. (2002) (supplemental text, available at www.jneurosci.org as supplemental material).

\section{Results}

Simultaneous whole-cell recordings were obtained from the soma and the cut, sealed end of the main axon from layer 5 cortical pyramidal cells $(n=40)$ in the ferret prefrontal cortex (Fig. 1), as detailed previously (Shu et al., 2006, 2007a,b). The distance from the axonal ending and the cell body varies from cell to cell, ranging from 24 to $430 \mu \mathrm{m}$. The axonal recordings are obtained from the 3-5 $\mu \mathrm{m}$ diameter terminal "blebs" formed in response to cutting of the axon during the slicing procedure. These terminal blebs allow for the whole-cell recording of cortical axons at distances from the cell body that would otherwise not be possible. Once simultaneous whole-cell recordings from the soma and axon were formed, action potentials were initiated through the intrasomatic injection of either depolarizing current pulses (typically $500 \mathrm{~ms}$ ) or a mixed excitatory-inhibitory noisy conductance (using a dynamic-clamp system) (see Materials and Methods) that caused a $10-25 \mathrm{mV}$ (peak to peak) deviation in membrane potential meant to mimic the variance naturally occurring in cortical pyramidal cells in vivo (Paré et al., 1998; Destexhe et al., 2003; Rudolph et al., 2005). These currents were injected into the soma, as opposed to the axon, because of the normal direction of flow of nearly all synaptic activity, which is from the dendrites, through the soma, and into the axon.
As reported previously, somatic action potentials in layer 5 pyramidal cells exhibited a rapid rate of rise at their base, giving rise to the appearance of a "kink" (Fig. 1a), whereas action potentials recorded at $30-70 \mu \mathrm{m}$ along the axon from the soma, in the axon initial segment, exhibited a much smoother trajectory leading up to action potential generation (Fig. $1 d$ ). This smoothness was only observed at the axon initial segment (where spikes are initiated) (Stuart et al., 1997a; Palmer and Stuart, 2006; Shu et al., 2007b), because whole-cell recordings further down the axon again exhibited a rapid rate of rise at the base of the spike (Fig. $1 g, l)$. Examination of $d V / d t$ for somatic action potentials revealed two components on the rising phase of the spike. The first component is classically known as the AIS spike (Coombs et al., 1957), whereas the second component originates in the somatodendritic portions of the neuron (Fig. 1b; supplemental Fig. 1, available at www.jneurosci.org as supplemental material). Phase plots of $d V / d t$ versus membrane potential ( $V$ ) for somatic spikes $(n=40)$, in which the rate of change of the membrane potential with respect to time $(d V / d t)$ is plotted as a function of $V$, exhibited two components, revealing a biphasic rate of rise to spike generation (Fig. 1c; supplemental Figs. 3, 4, available at www. jneurosci.org as supplemental material). In contrast, examination of $d V / d t$ and phase plot of $d V / d t$ versus $V$ for spikes in the axon initial segment revealed a single, monophasic, component during the rising phase of the spike (Fig. $1 e, f)(n=10)$. Wholecell recordings from distal axons demonstrated two components in the rising phase in $d V / d t$ and phase plots of $d V / d t$ versus $V$ (Fig. $1 h, i)(n=6)$, similar to that of somata, but dissimilar to that of the axon initial segment. The precise origin of the kink in the action potential in somatic recordings, the smoothness of action potential initiation in the axon initial segment recordings, and the biphasic nature of spike initiation at sites away from the axon initial segment is explored through Hodgkin-Huxley models, presented below.

Previously, it has been demonstrated that action potentials in layer 5 pyramidal cells initiate in the axon initial segment, $\sim 40$ $\mu \mathrm{m}$ from the soma (Stuart et al., 1997a; Palmer and Stuart, 2006; Shu et al., 2007b). Similarly, we found here that comparing the latency of spike arrival in the soma versus the axonal recordings yielded minimal spike latency at $\sim 42 \mu \mathrm{m}$ from the soma, confirming the initiation of action potentials at this location (Fig. 1j). Examination of spike threshold (defined by the membrane potential at which $d V / d t$ of the spike crossed $15-20 \mathrm{mV} / \mathrm{ms}$ ) revealed a steady hyperpolarization with increases in distance from the soma of 50-450 $\mu \mathrm{m}$ (Fig. $1 k$ ). The membrane potential at spike initiation was also more negative at the soma than at the initial portions of the axon (Fig. $1 k$ ). Interestingly, examination of the slope of the $d V / d t$ versus $V$ phase plot at a criteria level of $15 \mathrm{~V} / \mathrm{s}$ exhibited a strong decrease from the soma to the axon initial segment, followed by an increase at more distal portions of the axon (Fig. 1l). This measure, which we term "phase slope," has been used to measure the "kinkiness" of action potentials at their onset (Naundorf et al., 2006; McCormick et al., 2007). The point of the lowest phase slope corresponds precisely to the location of action potential initiation (Fig. $1 j, l)$.

\section{Hodgkin-Huxley models of spike propagation explain rapid spike initiation}

We sought to explain the properties of spike initiation in real cortical pyramidal cells, as detailed above, through HodgkinHuxley models. For clarity, we started with a simple model of propagating spikes and then added complexity as appropriate, 

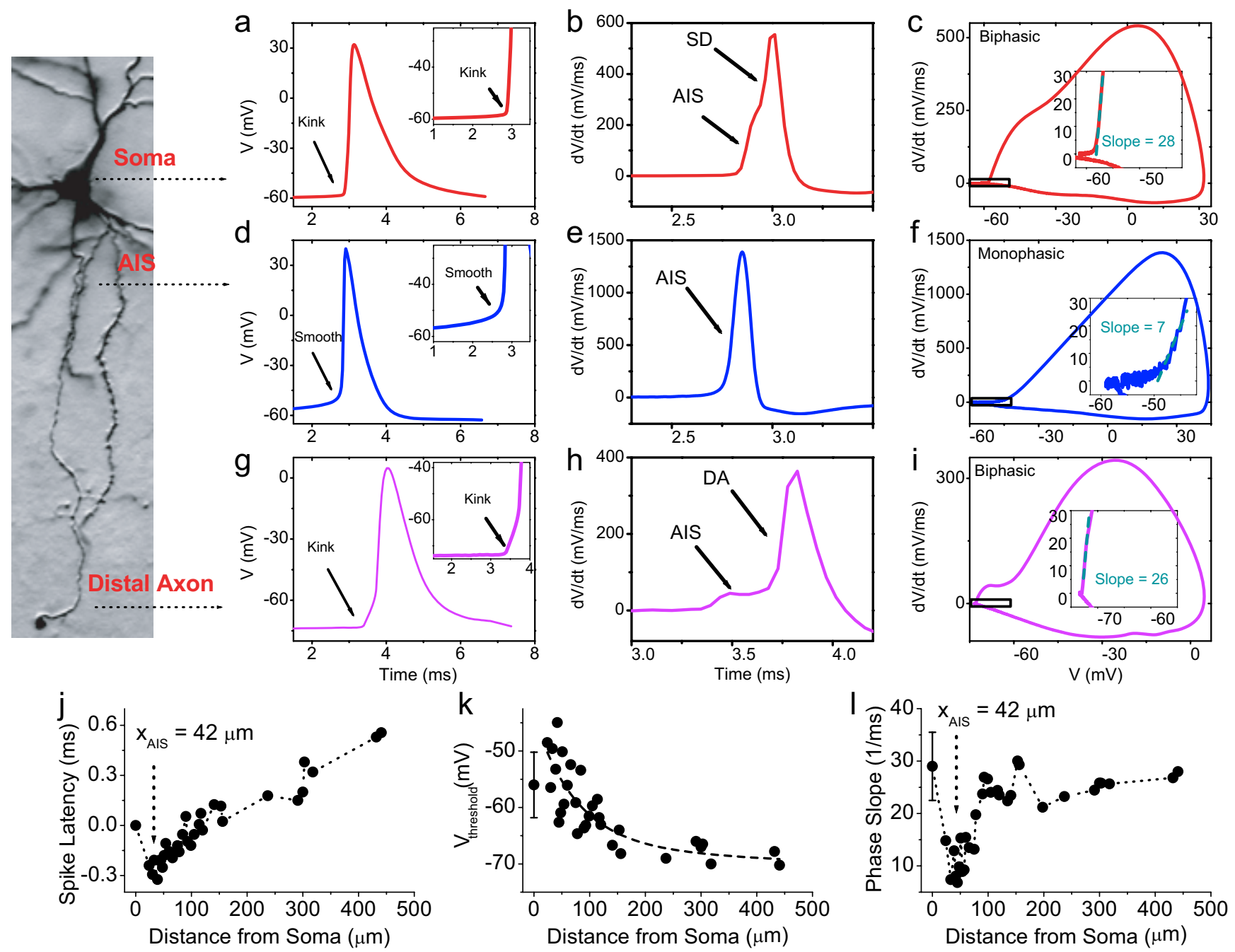

Figure 1. Action potential properties vary along somatic-axonal locations in cortical layer 5 pyramidal cells. $\boldsymbol{a}-\boldsymbol{c}$, Somatic whole-cell recording of a typical action potential showing the amplitude time course $(\boldsymbol{a}), d V / d t(\boldsymbol{b})$, and the phase plot of $d V / d t$ versus $V(\boldsymbol{c})$. Somatic action potentials exhibit a rapid rate of rise at initiation (kink) and two clear components in $d V / d t$. SD, Somadendritic. The phase plot is biphasic because of the two components of the action potential, with the AIS component causing the kink. $\boldsymbol{d}-\boldsymbol{f}$, Action potentials as recorded at the axon initial segment. Note the smooth onset $(\boldsymbol{d})$, the single component in $d V / d t(\boldsymbol{e})$, and the monophasic phase plot of $d V / d t$ versus $V(\boldsymbol{f}) . \boldsymbol{g}-\boldsymbol{i}$, Appearance of action potentials in the distal axon. Note the reappearance of a rapid rate of rise at onset (kink) $(\boldsymbol{g})$, the two components in $d V / d t[A I S$ and distal axon (DA)] (h), and the biphasic nature of spike generation (i). $\boldsymbol{j}$, Plot of the spike latency at different points along the axon (soma-axon) with simultaneous somatic and axonal recordings reveal the spike initiation point to be $\sim 42 \mu \mathrm{m}$ from the soma. $\boldsymbol{k}$, Plot of the membrane potential at spike onset reveals an exponential decrease along the axon. Note that the voltage at spike threshold in the soma is more negative than in the axon initiation point. $I$, Slope of the phase plot at spike threshold versus distance from the soma. Note that the phase slope decreases from the soma to the spike initiation point and then increases as the spike propagates down the axon. Each axonal point in $j-I$ represents results from a unique neuron.

finishing with a model of a large layer 5 pyramidal cell similar to those recorded with our whole-cell recording techniques. First, we examined the properties of action potentials as they propagate along a uniform cylindrical tube or "axon" (Fig. 2).

Our simple model started with a uniform axon ( $1 \mu \mathrm{m}$ diameter, $2 \mathrm{~mm}$ length) that contained an even distribution of a traditional Hodgkin-Huxley-style transient $\mathrm{Na}^{+}$current and a "delayed rectifier" $\mathrm{K}^{+}$current. Action potentials were initiated at one end of the uniform axon (termed $\mathrm{X}_{0}$ ) through the injection of a current pulse ( $100 \mathrm{~ms}, 0.1 \mathrm{nA})$, and spikes subsequently propagated (at a rate of $1.1 \pm 0.6 \mathrm{~m} / \mathrm{s}$ ) to the other end of the axon (termed $\mathrm{X}_{\text {end }}$ ) (Fig. 2a). Examination of the initiation properties of the action potential revealed that at the point of initiation, $\mathrm{X}_{0}$, the spike rose smoothly and slowly from baseline (Fig. 2b). This smooth rise at the point of initiation was also found in the phase plot of $d V / d t$ versus $V$ (Fig. $2 c$ ). As the action potential propagated down the uniform axon, the local spike exhibited a greater and greater rate of rise at the foot of the spike, giving it a kinky appearance (Fig. 2b). This was also observed in the phase plots of $d V / d t$ versus $V$ (Fig. 2c, inset). Plotting the slope of the phase plot at the criterion level (15-20 mV/ms) (see Materials and Methods) versus distance along the model axon revealed that the slope was low at the point of initiation, but rose rapidly to a peak at $\sim 300-400 \mu \mathrm{m}$ from the initiation point and depended on the values of $C_{\mathrm{m}}$ and $R_{2}$ (supplemental Fig. 5, available at www. jneurosci.org as supplemental material).

From these results, we hypothesized that the effects of spike propagation on spike shape arose from the properties of axial current flow and its interaction with membrane resistance and capacitance. It can be shown that for a propagating spike in a uniform axon, the rate of change of membrane potential with respect to time in a given axonal compartment obeys the following relationship: 

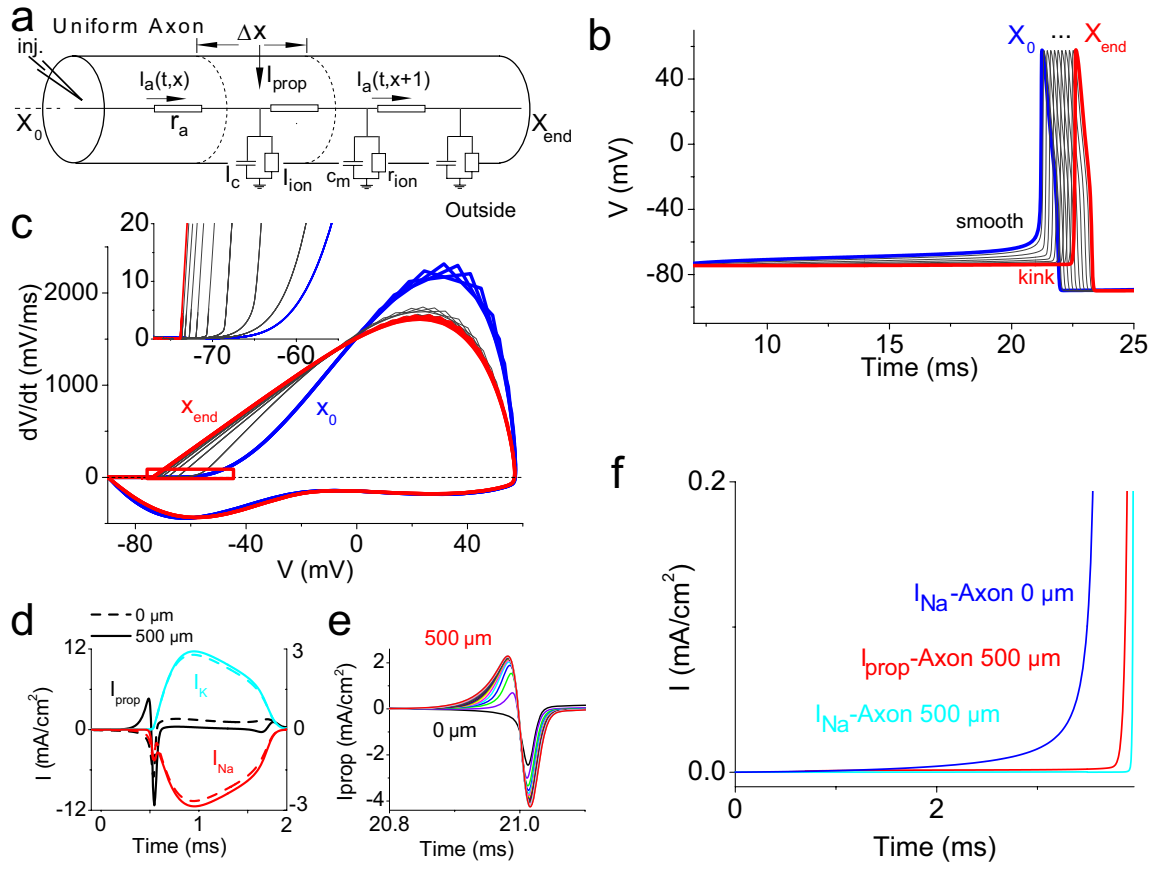

Figure 2. Hodgkin-Huxley model predicts the increase of the rapidity of spike initiation and decrease in voltage at threshold with spike propagation. $\boldsymbol{a}$, The axon model consists of a long uniform tube with axial resistance $\left(r_{a}\right)$ along which axial current $\left[I_{\mathrm{a}}(t, x)\right]$ flows. The membrane currents consist of $I_{\mathrm{C}}$ and $I_{\text {ion, }}$ through $c_{\mathrm{m}}$ and $r_{\text {ion, }}$ respectively. Spikes are initiated by applying a depolarizing constant current pulse to one end of the uniform axon $\left(X_{0}\right) \cdot \boldsymbol{b}$, Action potentials as they appear along a model of a single, uniform axon (1 $\mu \mathrm{m}$ diameter, $2 \mathrm{~mm}$ in length, unmyelinated). At the point of spike initiation $\left(X_{0}\right)$, the spike onset is smooth (blue traces in $\boldsymbol{b}, \boldsymbol{c}$ ), but as the spike propagates, its onset becomes more and more rapid $\left(X_{\text {end }}\right)$ (red traces in $\left.\boldsymbol{b}, \boldsymbol{c}\right)$. $\boldsymbol{c}$, This increase in spike onset rapidity and increase in negativity of voltage at threshold is also seen in the phase plot of $d V / d t$ versus $V$. Inset, Expansion of the phase plot at spike onset to illustrate the marked increase in phase slope with propagation of the spike. $\boldsymbol{d}$, Plot of the three major currents at the point of spike initiation and a distance of $500 \mu \mathrm{m}$. Note that the $\mathrm{Na}^{+}$and $\mathrm{K}^{+}$currents are approximately the same at both locations, whereas the axial current $I_{\text {prop }}$ exhibits a strong positive current at $500 \mu \mathrm{m}$. $\boldsymbol{e}$, Amplitude time course of $I_{\text {prop }}$ from the beginning of the axon to a distance of $500 \mu \mathrm{m}$. $f$, Absolute amplitude time course of the currents responsible for depolarization of the membrane potential leading up to action potential generation in the model axon. Note that the early $\mathrm{Na}^{+}$current at the first part of the axon rises slowly with time. In comparison, $I_{\text {prop }}$ at a distance of $500 \mu \mathrm{m}$ rises very quickly (thus causing the appearance of a kink in the propagated action potential). Note also that the rapid rise of the membrane potential from $/$ prop also results in the more rapid activation of $I_{\mathrm{Na}}$ at a distance of $500 \mu \mathrm{m}$, compared with that at the beginning of the model axon.

$$
\frac{d V}{d t}=\frac{I_{\text {prop }}-I_{\text {ion }}}{C_{m}},
$$

where $I_{\text {prop }}$ represents the flow of current into the local compartment because of distal action potential generation. In HodgkinHuxley models of propagating spikes in a uniform cylinder, $I_{\text {prop }}$ can be defined by the following equation:

$$
I_{\text {prop }}=\frac{a}{2 R_{2}} \frac{\partial^{2} V(t, x)}{\partial x^{2}},
$$

or when expressed as a function of time during steady state propagation (Hodgkin and Huxley, 1952):

$$
I_{\text {prop }}=\frac{a}{2 R_{2} u^{2}} \frac{\partial^{2} V(t, x)}{\partial t^{2}},
$$

where $a$ is the radius of the axon, $R_{2}$ is the specific internal resistance, and $u$ is action potential conduction velocity (supplemental Fig. 6 and text, available at www.jneurosci.org as supplemental material). Comparing the amplitude time course of $I_{\mathrm{Na}}, I_{\mathrm{K}}$, and $I_{\text {prop }}$ at the point of spike initiation at the beginning of the axon with the same currents at an axonal compartment $500 \mu \mathrm{m}$ distant reveals that the amplitude time course of $I_{\mathrm{Na}}$ and $I_{\mathrm{K}}$ are approxi- mately the same, whereas that of $I_{\text {prop }}$ is markedly different (Fig. 2d; supplemental Fig. 7, available at www.jneurosci.org as supplemental material). At the point of spike initiation, $I_{\text {prop }}$ is a negative-going current during the early stages of spike generation, because of leak of current to adjacent compartments (Fig. $2 d, e$ ). However, at more than $\sim 50 \mu \mathrm{m}$ down the axon, $I_{\text {prop }}$ is a positive current that precedes the local activation of $I_{\mathrm{Na}}$ and $I_{\mathrm{K}}$ and thus precedes and leads to the local generation of the spike (Fig. 2d,e; supplemental Fig. 7, available at www.jneurosci.org as supplemental material). Thus, as the action potential actively propagates, $I_{\text {prop }}$ is responsible for the early depolarization of the membrane potential before local action potential generation. Once local processes are actively generating the spike, $I_{\text {prop }}$ becomes a negative current, because this compartment is generating a larger current than neighboring ones, and thus current flows away from the compartment under consideration. Examining the amplitude time course of $I_{\text {prop }}$ at different distances down the model axon reveals the development and marked increase in the positive component of this axial current with distance from the spike initiation site (Fig. 2e). The early time course of $I_{\text {prop }}$, occurring before the local activation of $I_{\mathrm{Na}}$ and $I_{\mathrm{K}}$, causes it to be the major contributor to the generation of the fast rate of rise of action potentials at spike onset during action potential propagation (e.g., the increase in kinkiness) (Fig. 2f; supplemental Fig. 7, available at www.jneurosci.org as supplemental material). In addition, because $I_{\text {prop }}$ is proportional to the rate of acceleration of the membrane potential with respect to time,

$$
\left(\frac{\partial^{2} V(t, x)}{\partial t^{2}}\right)
$$

$I_{\text {prop }}$ rises rapidly during the early portions of the propagating action potential, when the rate of positive change in $d V / d t$ is largest (Fig. $2 f$ ). This property of $I_{\text {prop }}$ causes it to generate a more rapid change in membrane potential for propagating spikes compared with those generated by the slowly rising $\mathrm{Na}^{+}$current at the site of spike initiation (Fig. 2f). An intuitive way of understanding this property is to realize that at the beginning of the axon, the spike initiates in response to a steady depolarization that is much less intense than that provided by an action potential. In contrast, the initiation of the spike further down the axon occurs in response to the explosive and intense (i.e., large current flow) discharge of neighboring membrane.

The changes in spike shape with propagation have an additional consequence on measures of spike threshold. If spike threshold is taken as the membrane potential at which a criteria level of $d V / d t$ is surpassed, then spike threshold will appear to decrease as the spike propagates along the axon (Fig. $2 b$ ). This results from the increased rapidity with which action potentials 
a Uniform axon

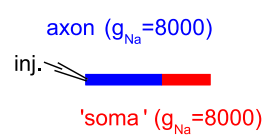

e Soma+Axon

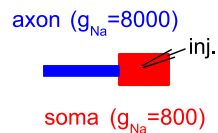

i Dend+Soma+Axon b

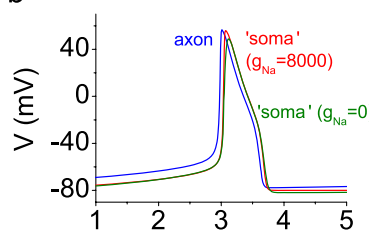

f

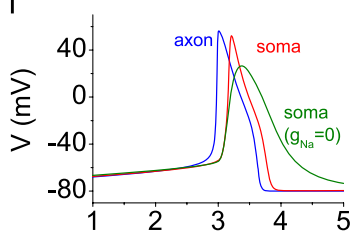

j

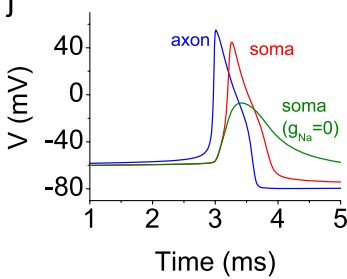

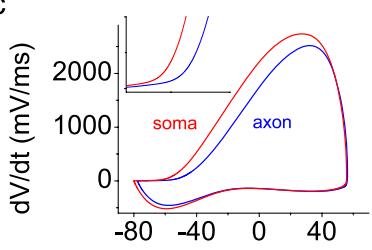

g d

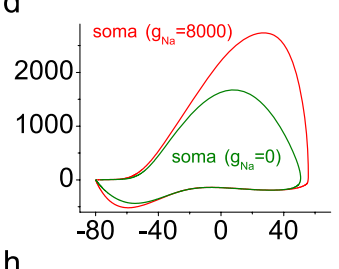

$\mathrm{h}$

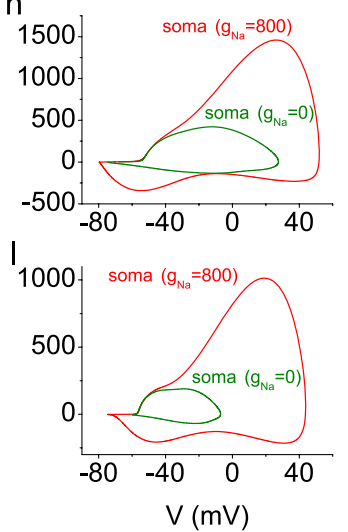

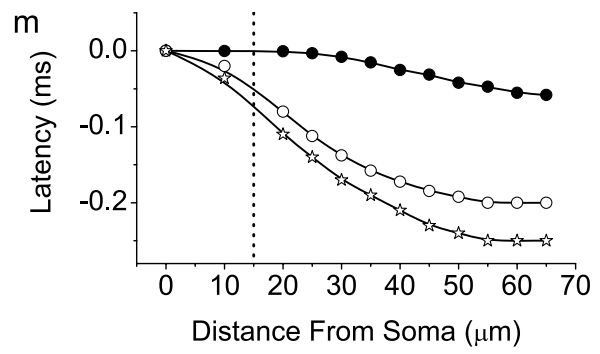

\section{k}
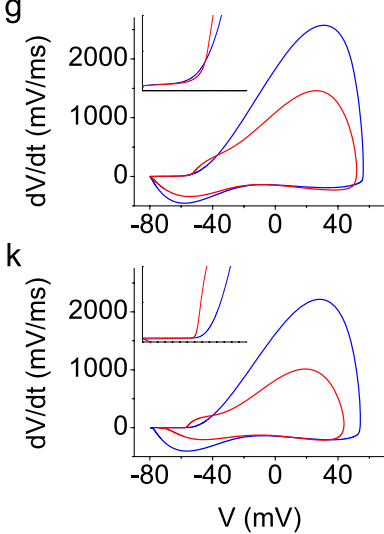

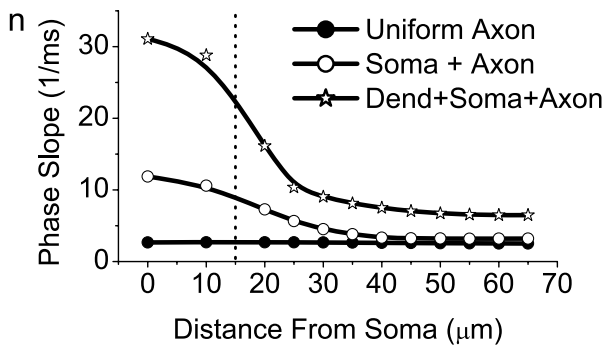

Figure 3. Simple model illustrating the effect of somatic and dendritic compartments on the backpropagation of axonally initiated action potentials. $\boldsymbol{a}-\boldsymbol{d}$, The simplest model consists of an 80 $\mu \mathrm{m}$ uniform axon, which we divide into a $30 \mu \mathrm{m}$ "somatic" region and a $50 \mu \mathrm{m}$ axonal region $(\boldsymbol{a})$. The somatic region had either the same density of $g_{\mathrm{Na}}$ as the axon $\left(8000 \mathrm{pS} / \mu \mathrm{m}^{2}\right)$ or no $g_{\mathrm{Na}} \cdot \boldsymbol{b}$, Illustrated are the action potentials in the somatic region (red, somatic $g_{\mathrm{Na}}=8000 \mathrm{pS} / \mu \mathrm{m}^{2} ;$ green, somatic $g_{\mathrm{Na}}=0 \mathrm{pS} / \mu \mathrm{m}^{2}$ ) and action potentials at the end of the axon (blue traces), where spikes are initiated with local current injection. $\boldsymbol{c}, \boldsymbol{d}$, Also illustrated are the phase plots ( $d V / d t$ vs $V$, of these action potentials in two conditions; $\boldsymbol{d})$ or two recording locations (c). $\boldsymbol{e}-\boldsymbol{h}$, Results after the somatic region is expanded to $30 \times 20 \mu \mathrm{m}$ (see Materials and Methods), and $g_{\mathrm{Na}}$ in the soma is either 800 (red traces) or 0 (green traces). Note that when somatic $g_{\mathrm{Na}}$ is reduced to 0 , the initial portions of the somatic action potential remain unaltered, indicating that this portion (which gives rise to the kink in rapidly rising spikes) arises from the propagation of the axonal spike into the somatic region. $\boldsymbol{i}-\boldsymbol{l}$, Results after the addition of a 3000- $\mu \mathrm{m}$-long dendritic region. The green traces follow removal of $g_{\mathrm{Na}}$ from both the soma and dendrite. $\boldsymbol{m}$, Addition of somatic and dendritic regions delays the backpropagation of action potentials from the axon into the soma. $\boldsymbol{n}$, The addition of the somatic and dendritic regions causes the slope of the phase plot at spike initiation (phase slope, which is a measure of the spike kink) to increase dramatically as the spike invades the somatic region. inj., Injection of current.

are initiated as they propagate along the axon, because of the axial flow of current. Greater rapidity of spike initiation lowers the apparent spike threshold by bringing the spike to the criteria level of $d V / d t$ at a more negative membrane potential (Fig. 2b). This result is comparable with that recorded in real axons (Fig. $1 \mathrm{k}$ ).

The change in shape of the action potential as it propagates through our simple axon model occurs over a spatial scale of $\sim 200-300 \mu \mathrm{m}$ (supplemental Fig. 5, available at www. jneurosci.org as supplemental material), which would seem to be too long of a distance to account for the hypothesized change in action potential shape associated with propagation from the axon initial segment into the cell body (a distance of $40-60 \mu \mathrm{m}$ ) in cortical pyramidal cells (Stuart et al., 1997a; Palmer and Stuart, 2006; Shu et al., 2007b). However, we hypothesized that the resistive and capacitive properties of the cell body (and attached dendrites) may cause more rapid changes with distance in spike shape than those occurring in uniform axonal compartments.

To test this hypothesis, we constructed a uniform axonal model and then modified portions of this model axon to mimic the addition of a soma-like compartment and then somatic and dendritic-like compartments (Fig. 3). In the initial model, a uni- form cylinder, the action potential was initiated at the end of the axon with DC injection and allowed to backpropagate to the other end (Fig. 3a). For comparison to subsequent models, we refer to the receiving end of the uniform axon as the "somatic" compartment. As predicted, the action potential in the somatic compartment of the uniform cylinder exhibited an apparent lower threshold than at the spike initiation point (Fig. 3c). Removing $g_{\mathrm{Na}}+$ from the somatic portion of the cylinder had only a small effect on the recorded action potential (Fig. 3b), reducing its peak $d V / d t$ (Fig. $3 d$ ).

Next, we changed the geometry of the somatic portion from the same dimensions as the rest of the axon to a cylinder $(20 \mu \mathrm{m}$ diameter, $30 \mu \mathrm{m}$ length) in which the density of $g_{\mathrm{Na}}$ was $10 \%$ of that in the axon. Thus, in this model, the backpropagating action potential from the axon encounters a point of sudden increase in conductance and capacitive load in which the ability to generate local $\mathrm{Na}^{+}$currents is reduced, as is the case in real cortical pyramidal cells (Komada and Soriano, 2002; Inda et al., 2006; Kole et al., 2007, 2008; Shu et al., 2007b). Comparison of the phase plot of $d V / d t$ versus $V$ of the somatic and axonal action potentials (Fig. $3 g$ ) reveal that somatic spikes have two components, as in real 

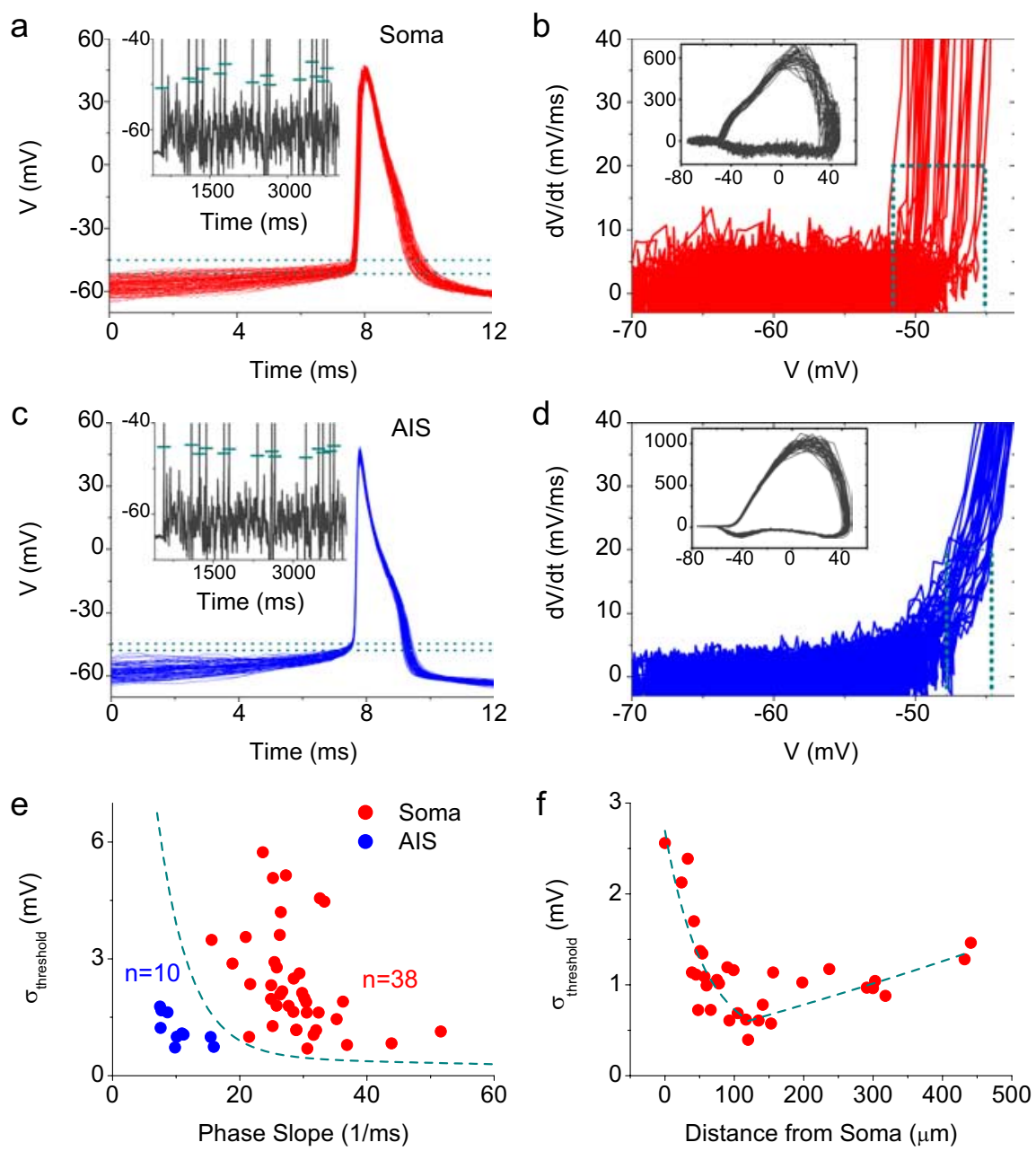

Figure 4. Spike onset variability varies along the somatic-axonal locations in cortical layer 5 pyramidal cells in vitro. $\boldsymbol{a}$, The intrasomatic injection of a noisy conductance results in the initiation of action potentials that exhibit a rapid onset and variable membrane potential at threshold (indicated by dashed lines) as recorded at the soma. $\boldsymbol{b}$, Phase plot ( $d V / d t v s V$ ) of the spikes in the soma reveals their biphasic nature (inset) as well as their variable voltage at spike onset. $\boldsymbol{c}, \boldsymbol{d}$, Spikes at the axon initial segment reveal a smoother spike onset and less variability in voltage at onset $(\boldsymbol{d})$ than in the simultaneously recorded somatic spikes $(\boldsymbol{a}, \boldsymbol{b})$. $\boldsymbol{e}$, Plot of the SD of threshold voltage ( $\sigma_{\text {threshold }}$ ) versus the slope of the phase plot at spike threshold (defined as a $d V / d t$ of 20 $\mathrm{mV} / \mathrm{ms}$ ) reveals that action potentials at their site of initiation in the axon exhibit both a low threshold variability and low phase slope, whereas somatic spikes exhibit a higher variability and higher phase slope. $f$, Spike threshold variability as a function of distance from the soma. Note that prespike $V_{m}$ variability along the axon decreases from the soma to the initial portions of the axon and then slowly increases along the axon. The points in $\mathbf{e}$ and frepresent different neurons, except that all axonal recordings in e were obtained simultaneously with somatic recordings in the same neurons.

neurons (Coombs et al., 1957; Colbert and Pan, 2002; Shu et al., 2007b). In addition, in this simple model the peak $d V / d t$ of the somatic spike is substantially lower than at the axonal initiation site. Note also that the spike in the soma has a faster rate of rise at initiation (Fig. $3 g$ ). Reducing $\mathrm{g}_{\mathrm{Na}}$ in the somatic compartment to 0 blocks the somatically generated action potential, revealing the propagated axonal spike only (Fig. $3 f, h$, green trace). Note that the initial portions of the somatic spike are unchanged, including the rapid rate of spike rise at initiation. This result indicates that the rapid rate of rise of the action potential in the model soma results entirely from the properties of the propagated axonal spike.

To examine these issues further, we added a single artificial dendrite to our soma and axon model, thus increasing the conductance and capacitive load on the axonal spike generator. To be conservative, the model dendrite provided a capacitive and conductance load on the soma that was even less than that of a full dendritic arbor of a layer 5 pyramidal cell (see Materials and Methods). In the axonsoma-dendrite model, somatic spikes appeared more kinky than at the axon initiation site (Fig. $3 j, k$ ) and the phase plot of $d V / d t$ versus $V$ exhibits a clear biphasic rise (Fig. 3k), as in our recordings from layer 5 pyramidal cells (Figs. 1c, 4b). Removing $\mathrm{g}_{\mathrm{Na}}$ from the soma (and dendrite) in this model again left the initial phases of spike initiation intact, revealing that this rapid rate of rise at the foot of the spike results entirely from the properties of spike propagation from the axon into the soma and dendrite (Fig. 3l)

Examination of the onset latency of action potentials revealed that the addition of a soma or soma and dendrite resulted in a significant decrease in velocity (Fig. $3 m$ ). This decrease in velocity results from the delay from the invasion of the soma by the axonal spike and local spike initiation. The delay, and thus the biphasic nature, results from the decreased $\mathrm{Na}^{+}$channel density and the increased conductance and capacitive load of the soma and dendrite compared with the axon. The addition of a soma or soma and dendrite had a significant facilitating effect on the slope of the phase plot of somatic spikes (Fig. 3n). It should be noted that even in the uniform axon, the phase slope increases with propagation, but to an extent that is difficult to see on this scale (supplemental Fig. 5, available at www.jneurosci.org as supplemental material).

These results indicate that the rapid rate of rise of action potentials at the soma, as recorded in real neurons can be explained by the backpropagation of action potentials into the conductance and capacitive load of the soma and dendritic arbor, because of the properties of axial current flow. As the action potential propagates, it provides a strong and rapidly increasing, with respect to time, axial current that rapidly depolarizes the somatic membrane potential at spike initiation, giving rise to the kink observed with in vivo and in vitro intracellular recordings. We have explored a wide variety of different concentrations of $\mathrm{Na}^{+}$and $\mathrm{K}^{+}$conductances, as well as somatic and dendritic membrane areas (and thus conductance and capacitive loads) and find that our result are robust to a broad range or parameters, as long as the spike is initiated in the axon and backpropagates into the soma/dendrite (data not shown).

\section{Action potential variability in recorded layer 5 pyramidal cells}

Previous investigations have emphasized the marked variability of action potentials as recorded from the somata of cortical neurons (Azouz and Gray, 1999, 2000; Henze and Buzsaki, 2001). Here, we sought to examine the contribution of spike propagation to this variability through simultaneous somatic and axonal 
whole-cell recordings in layer 5 pyramidal cells in vitro during the initiation of action potentials with a noisy current injection. Because the large majority of synaptic potentials arrive at the axon initial segment by passing through the soma, we chose to inject the noisy current (or conductance with a dynamic clamp system) through the somatic pipette (as opposed to injection of noise directly into the axon).

The intrasomatic injection of a noisy conductance resulted in the initiation of action potentials in the axon initial segment that then backpropagated into the soma (Fig. 4). Examination of the $d V / d t$ versus $V$ phase plots revealed a greater variability in somatic membrane potential at action potential threshold than in the simultaneously recorded axon initial segment (Fig. $4 a-d$ ). Plotting the SD of voltage at spike threshold versus the slope of the $d V / d t$ versus $V$ phase plot at the criterion level for action potential threshold (15-20 mV/ms) (see Materials and Methods) revealed two nonoverlapping clusters of points corresponding to axon initial segment and somatic recordings (Fig. 4e). Action potentials at the axon initial segment are characterized by a low phase slope at spike onset $\left(10 \pm 3 \mathrm{~ms}^{-1}\right)$ as well as low variability in spike threshold voltage $(\mathrm{SD}, 1.18 \pm 0.38 \mathrm{mV}$ ), whereas action potentials in the soma exhibit significantly higher values in both of these measures (phase slope, $28.8 \pm 6.4 \mathrm{~ms}^{-1}$; SD threshold, $2.4 \pm 1.3 \mathrm{mV} ; p<0.01$ ) (Fig. 2e). Interestingly, plotting the variability of the membrane potential at spike threshold at different axonal distances from the cell body revealed a decrease to a minimum of $\sim 50-150 \mu \mathrm{m}$ from the soma, followed by a slow increase up to the furthest recording points ( $\sim 430 \mu \mathrm{m}$ from the soma) (Fig. $4 f)$ ( $n=32$ axon recordings). Examining the simultaneous somatic and axonal recordings revealed that the apparent large variability of the somatic action potential threshold originates from variations in differences between the somatic and axonal membrane potentials leading up to spike generation (supplemental Fig. 8, available at www.jneurosci.org as supplemental material) (see below).

Together, these results indicate that at the point of spike initiation, the axon initial segment, action potentials develop smoothly and with relatively low variance in membrane potential threshold. As these spikes propagate to either the soma or down the axon, they become (1) more kinky or rapid in their rate of rise at initiation, (2) exhibit a biphasic process in their rising phase, and (3) exhibit greater variability in their apparent spike threshold when spikes are initiated by a noisy process.

\section{Hodgkin-Huxley models predict increased spike threshold variance with spike propagation}

The injection of noisy currents or conductances into the soma of cortical neurons results in a higher degree of spike threshold variance than found in the simultaneously recorded axon, at or uniform axon

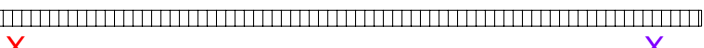

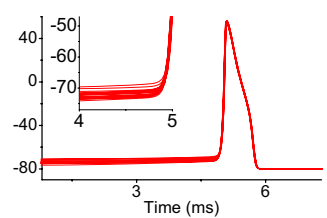

e

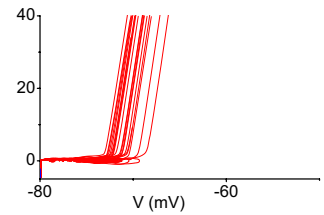

$\mathrm{h}$

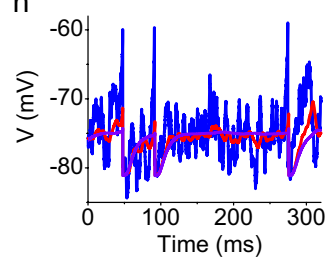

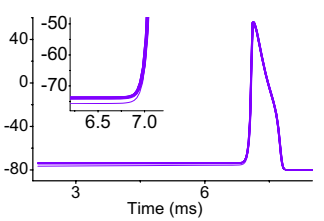

$f$
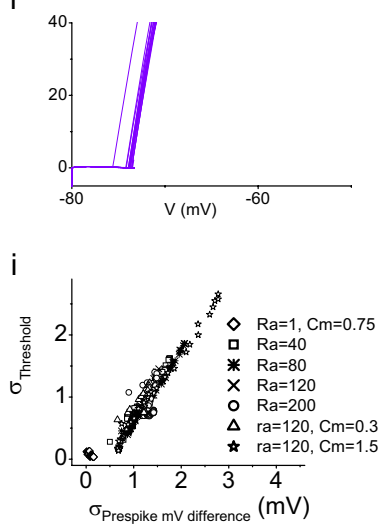

Figure 5. Spike propagation results in apparent changes in spike threshold variability. The model consisted of a single long, uniform axon. Action potentials were initiated through the injection (inj.) of conductance noise at the end of the model axon, $X_{0}$. $\boldsymbol{a}-\boldsymbol{c}$, Action potentials are illustrated as they appear at $\mathrm{X}_{0}$ ( $\boldsymbol{a}$; blue traces), $400 \mu \mathrm{m}$ down the axon at $X_{1}(\boldsymbol{b}$; red traces), and at the $X_{1}$ (compared with point $X_{0}$ ) and a decrease at point $X_{\text {end }}$ back to levels similar to those seen at point $X_{0} . g$, Plot of the SD of spike e the during noise injection at the three rording points. Note the decrease in noise at point $X_{1}(r e d)$ and the near spike threshold plotted as a function of the variation in membrane potential 1 ms before spike initiation locally and at the spike intiation point. Note that under a wide range of values for axial resistance and membrane capacitance, there is a strong and linear

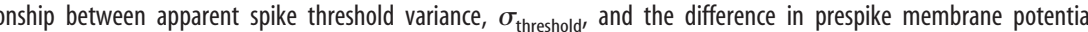
spike propagates nearly instantaneously (when $R_{2}=1, C_{\mathrm{m}}=0.75$ ), there is very little variance in spike threshold at all points along the axon. Each point represents an increment of $50 \mu \mathrm{m}$ along the axon.

near the spike initiation zone (Fig. 4). Here, we sought to investigate the mechanisms of this increased somatic spike threshold variability with simple models of spike propagation.

First, we modeled a uniform axon in which action potentials were initiated at point $\mathrm{X}_{0}$ (the beginning of the axon), followed by propagation to the end, denoted as point $\mathrm{X}_{\text {end }}$ (Fig. 5). As before, the spikes at the point of initiation exhibited a smooth rise at spike initiation, whereas spikes further down the uniform axon exhibited a stronger and stronger kink (Fig. $5 a-c$ ). Interestingly, the membrane potential variability at spike initiation was greater at a midway point $\left(\mathrm{X}_{1}\right)$ compared with the point of spike initiation $\left(\mathrm{X}_{0}\right)$ or further down the axon $\left(\mathrm{X}_{\text {end }}\right)$ (Fig. $5 a-g$ ). This is true, although the level of subthreshold variance decreased strongly along the model axon with increases in distance from the noise injection site (Fig. $5 d-f, h$ ). Plotting the SD of spike threshold versus distance down the model axon illustrates an increase up to $\sim 300 \mu \mathrm{m}$, followed by an exponential decrease with further increases in distance (Fig. $5 g$; supplemental Fig. 9, available at www.jneurosci.org as supplemental material).

We examined this behavior of propagating action potentials in more detail by comparing the membrane potential deviations 


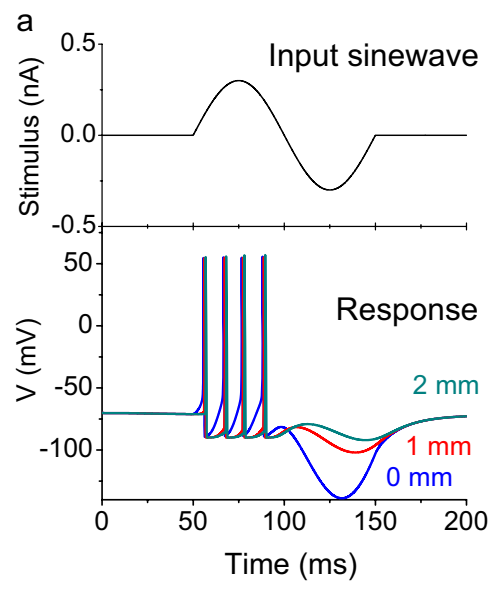

b Subthreshold $\mathrm{Vm}$ time delay

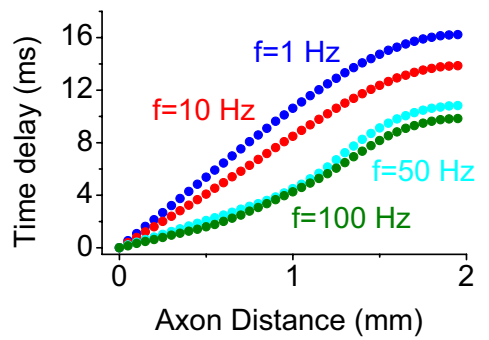

Figure 6. Propagation of subthreshold membrane potential changes along a model axon results in frequency-dependent phase shifts. $\boldsymbol{a}$, Sine waves of varying frequencies $(1,10,50,100 \mathrm{~Hz})$ were injected into one end of a 2-mm-long model axon. Note the variation of the phase relationship of the subthreshold membrane potential with distance ( $10 \mathrm{~Hz}$ sine wave is illustrated). $\boldsymbol{b}$, Time delay of subthreshold membrane potential variations for the different sine-wave frequencies injected. c, Phase relationship between the first action potential and the injected sine wave with distance and frequency. Note the frequency-dependent change in phase relationship between the spikes and injected sine wave. The phase relationship at the point of origin (the beginning of the axon) was taken as zero. In this plot, the radius is the distance along the axon. $\boldsymbol{d}$, Phase shift of subthreshold membrane potential changes with distance is frequency dependent. These results indicate that as a complex waveform and action potentials propagate along a process, the timing relationship between the action potentials and the various frequency components of the waveform will be considerably rearranged (because of frequency-dependent phase shifts), resulting in the appearance of an increase in spike threshold variance.

at the point of spike initiation to those at the point along the axon in which the spike threshold variance was greatest during noisy current injection (Fig. 5h) and by examining the frequency dependence of phase shifts in the membrane response of model axons to sinusoidal current injections (Fig. 6). As expected from the filtering properties of a cable, higher frequencies are filtered greater than lower frequencies (Shu et al., 2006) and there are significant frequency-dependent phase shifts in the fluctuating membrane potential as it propagates down the axon (Fig. 6). The interaction of these frequency-dependent phase shifts, amplitude filtering, and action potential propagation speed results in a remixing of the membrane potential deviations that occur just before local spike generation at each point along the axon (Fig. 6). Thus, comparing the membrane potential just before spike generation at a midpoint $\left(\mathrm{X}_{1}\right)$ in the axon to the site of spike initiation $\left(\mathrm{X}_{0}\right)$ during noisy current injection reveals that the degree of depolarization at point $\mathrm{X}_{1}$ varies greatly from spike to spike, causing an apparent high degree of membrane potential variability of apparent spike threshold (Fig. 5). In other words, some spikes are initiated at point $\mathrm{X}_{0}$ when point $\mathrm{X}_{1}$ is depolarized (taking into account action potential propagation delay), thus causing the spike to appear to have a high threshold. Other spikes are initiated at point $\mathrm{X}_{0}$ when $\mathrm{X}_{1}$ is less depolarized (or, theoretically, even hyperpolarized; again taking into account propagation delays), giving the impression at point $\mathrm{X}_{1}$ that the spike has a low threshold.

Because the subthreshold variance is filtered as it propagates down the axon, it eventually becomes a marginal influence on local spike threshold variations (Fig. $5 g$ ). Thus, the apparent variability initially rises with distance from the spike initiation site (resulting from filtering and phase shifting of the subthreshold variations) (Fig. 6), but then apparent spike threshold variability decreases with further increases in distance, as the local membrane potential variations become smaller and smaller. We hypothesized that this spike threshold variance is related to differences in membrane potential at the site of spike initiation and at the more distal site down the axon. To examine this hypothesis more thoroughly, we plotted the variation in spike threshold at point $\mathrm{X}_{1}$ against the variation of the difference in membrane potential $\left(\mathrm{X}_{1}-\mathrm{X}_{0}\right)$ just before spike generation at point $\mathrm{X}_{1}$ versus point $\mathrm{X}_{0}$ (denoted as prespike $V_{\mathrm{m}}$ difference) (Fig. 5i; supplemental Fig. 9, available at www. jneurosci.org as supplemental material). There is a high correlation between these two variables $(r=0.99 ; p<0.01)$, indicating that a high degree of variability between membrane potentials just before spike initiation at $\mathrm{X}_{1}$ and $\mathrm{X}_{0}$ is associated with a high degree of spike threshold variance at point $\mathrm{X}_{1}$. By varying the axial resistance $\left(R_{2}\right)$ and specific membrane capacitance $\left(C_{\mathrm{m}}\right)$ we found that increases in threshold variance with propagation was dependent on the filtering properties (and action potential propagation speed) exhibited by the axon. For example, in conditions in which axial resistance was minimal $\left(R_{2}\right.$ $=1$ ), resulting in high action potential conduction velocity, the variation in spike threshold was also minimal (Fig. 5i). Similarly, when axial resistance was raised along with specific membrane capacitance, thereby slowing action potential conduction velocity as well as altering the filtering properties of the axon, the variation in apparent spike threshold was increased as well as the variation in differences of membrane potential before spike generation at the point of spike initiation $\left(\mathrm{X}_{0}\right)$ and the midpoint of the axon $\left(\mathrm{X}_{1}\right)$ (Fig. 5i). These results indicate that when spikes propagate away from a noise source, spike threshold variance is expected to rise to a peak value and then fall with further increases in distance. Importantly, propagation of action potentials toward a noise source (as occurs in real neurons undergoing injection of a noisy conductance in the soma) results in a progressive increase in spike threshold variance with propagation (supplemental Fig. 10, available at www.jneurosci.org as supplemental material).

Next we compared results across three simple models: (1) a uniform axon; (2) a uniform axon attached to a cylindrical soma; and (3) a uniform axon attached to a cylindrical soma and dendrite (Fig. 7). In all of these models, conductance noise was injected into the soma (the "soma" end in the case of the uniform 

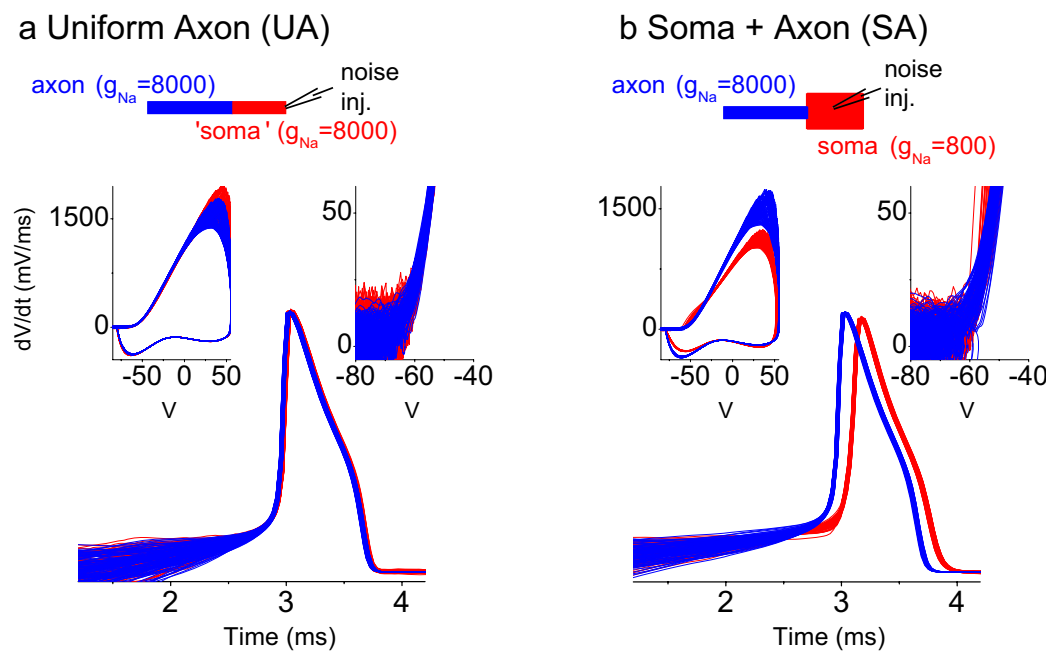

f
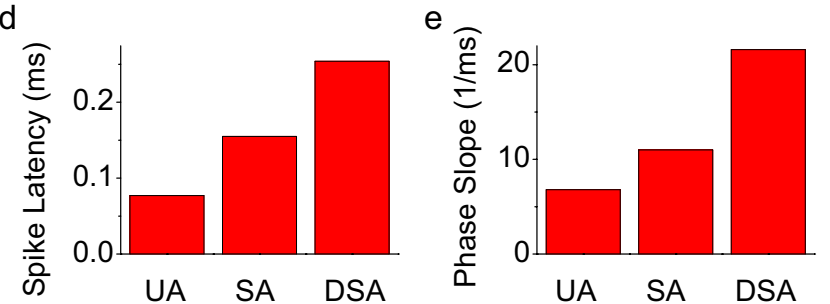

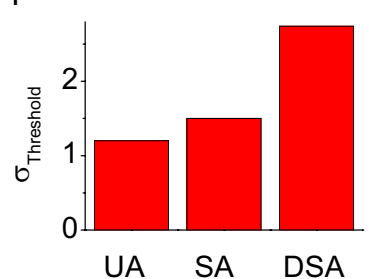

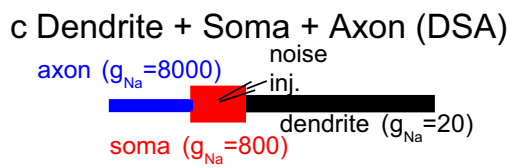

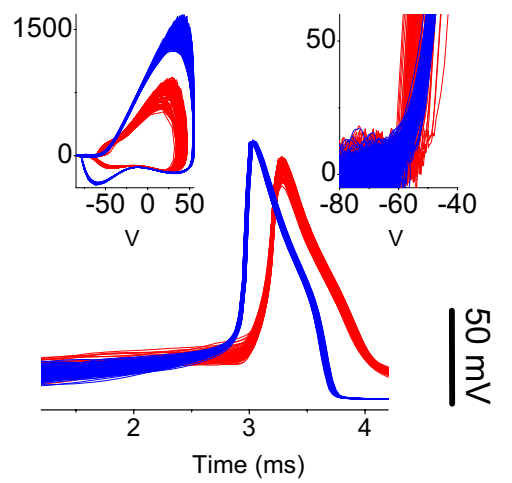

Figure 7. Addition of somatic and dendritic compartments increases apparent spike threshold variability in the soma. $\boldsymbol{a}$, Spikes at the two ends of a model axon. Noise is injected into the somatic (red) region, and spikes are initiated at the opposite end (blue). $\boldsymbol{b}$, Increasing the diameter of the somatic portion to $20 \mu \mathrm{m}$ results in a significant delay in the invasion of the somatic compartment by the backpropagating axonal action potentials. This delay is associated with a biphasic phase plot, an increase in kinkiness of action potential onset, and an increase in apparent spike onset variability in the somatic region (red traces). $c$, Addition of a dendritic compartment causes the spikes in the soma to be further delayed, to have a more pronounced biphasic phase plot, and to exhibit an increase in apparent spike onset variability. $\boldsymbol{d}-\boldsymbol{g}$, Plot of somatic spike latency (d), slope of the phase plot of $d V / d t$ versus $V$ at spike onset in the soma $(\boldsymbol{e})$, SD of somatic spike threshold $(\boldsymbol{f})$, and SD of difference in prespike membrane potential at the point of spike initiation versus the soma $(\boldsymbol{g})$. Note that the addition of a soma or of a soma and dendrite causes all of these parameters to rise together.

axon) and spikes initiated at the far end of the axonal segment, resulting in backpropagation of the spike into the soma (and dendrite in Fig. $7 c$ ). As in Figure $3 a$, we initially distributed $g_{\mathrm{Na}}$ and $g_{\mathrm{K}}$ such that there was a uniform density throughout the cylindrical soma and axon $\left(\mathrm{g}_{\mathrm{Na}}=8000 \mathrm{pS} / \mu \mathrm{m}^{2} ; \mathrm{g}_{\mathrm{K}}=1600 \mathrm{pS} /\right.$ $\mu \mathrm{m}^{2}$ ). With the addition of a soma or soma and dendrite, we reduced the density of $g_{\mathrm{Na}^{+}}$and $g_{\mathrm{K}}+$ in each of these (soma: $\mathrm{gNa}$, $800 \mathrm{pS} / \mu \mathrm{m}^{2} ; g_{\mathrm{K}}, 320 \mathrm{pS} / \mu \mathrm{m}^{2}$; dendrite: $g_{\mathrm{Na}}, 20 \mathrm{pS} / \mu \mathrm{m}^{2} ; g_{\mathrm{K}}, 10$ $\mathrm{pS} / \mu \mathrm{m}^{2}$ ) (see Materials and Methods). The addition of a soma and especially a soma and dendrite increased spike latency (Fig. $7 d$ ), enhanced the biphasic nature of spike generation (Fig. 7a-c), increased the rate of rise of the membrane potential at spike threshold (Fig. 7e), and increased the variation of membrane potential at spike threshold in the soma (Fig. $7 f, g$ ).

\section{Morphologically realistic Hodgkin-Huxley models of pyramidal cells exhibit rapid somatic spike onset and variability}

We next examined whether a more complete model of a cortical pyramidal cell would yield action potentials with properties similar to those of real pyramidal cells (Fig. 8; supplemental Fig. 13, available at www.jneurosci.org as supplemental material). For this purpose, we used a modified version of the model of a layer 5 pyramidal cell constructed by Mainen and Sejnowski (Mainen et al., 1995; Mainen and Sejnowski, 1996). In this model, we attached a cylindrical axon initial segment (1.2 $\mu \mathrm{m}$ diameter, 50 $\mu \mathrm{m}$ length) to the fully reconstructed soma-dendritic arbor of a layer 5 pyramidal cell (Fig. 8). The axon initial segment was followed by a $500-\mu \mathrm{m}$-long segment of myelinated axon. Immunohistochemical evidence suggests that the axon initial segment of cortical pyramidal cells contains a high concentration of $\mathrm{Na}^{+}$ channels (Komada and Soriano, 2002; Inda et al., 2006; Kole et al., 2008). Although the precise density of $\mathrm{Na}^{+}$channels in the axon initial segment is not known, these immunohistochemical studies suggest that it may be as high at the node of Ranvier, where $\mathrm{Na}^{+}$channel densities are in the range of $20-30 \mathrm{nS} / \mu \mathrm{m}^{2}$ (Black et al., 1990; Waxman and Ritchie, 1993; Waxman, 1995). Direct patch-clamp recordings from axon initial segments of cortical pyramidal cells have suggested that the density of $\mathrm{Na}^{+}$channels is between 3 and 50 times that of the soma (Colbert and Pan, 2002; Kole et al., 2008).

We used an empirical approach to determine the proper level of $\mathrm{Na}^{+}$and $\mathrm{K}^{+}$channel density to use in our model. We adjusted each until action potentials met the following criteria: (1) they initiated in the axon initial segment $\sim 35-50 \mu \mathrm{m}$ from the soma; (2) their peak $d V / d t$ in the soma and axon initial segment was similar to that recorded from real neurons; and (3) their amplitude and duration was similar to that of real pyramidal cells (Fig. 1) (supplemental Fig. 1, available at www.jneurosci.org as supplemental material). Using this approach, we found that a density of $g_{\mathrm{Na}^{+}}$of $750 \mathrm{pS} / \mu \mathrm{m}^{2}$ in the soma and $8000 \mathrm{pS} / \mu \mathrm{m}^{2}$ in the model axon initial segment gave rise to action potentials similar to those recorded in real layer 5 pyramidal cells (compare Figs. 1, 8). 

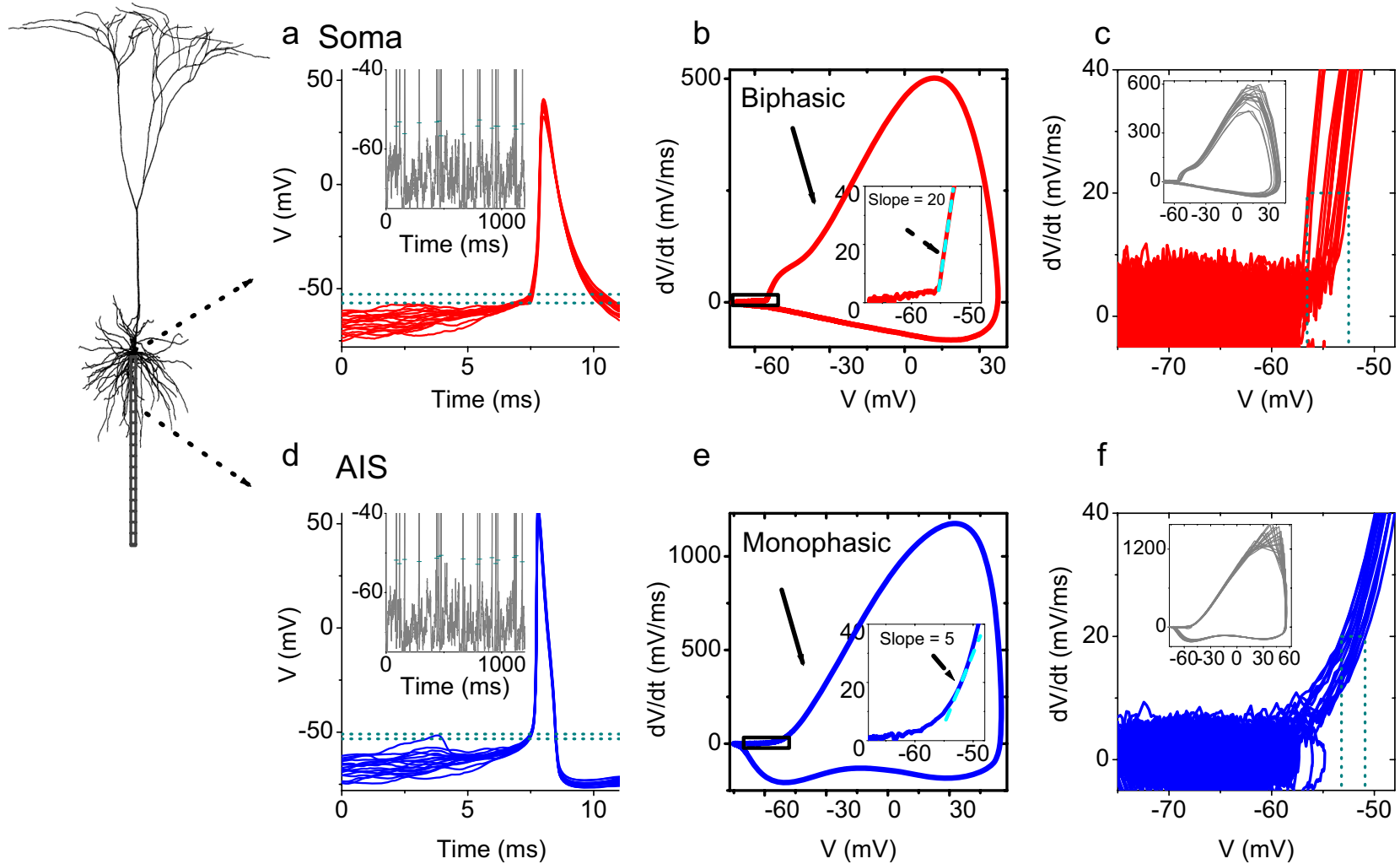

e
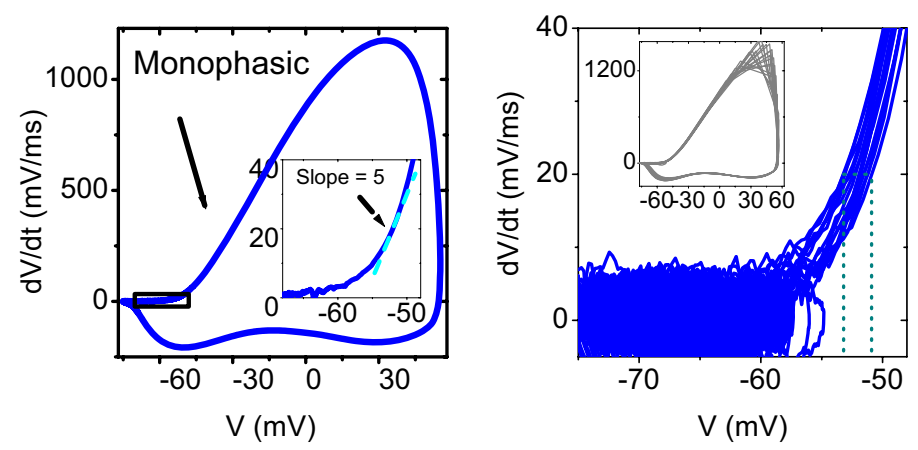

Figure 8. A full dendritic model of a layer 5 cortical pyramidal cell exhibits properties similar to those recorded in actual layer 5 cortical pyramidal cells. $\boldsymbol{a}$, Action potentials in the soma exhibit a kink and larger threshold variance (dashed horizontal lines). Inset illustrates $V_{m}$ response to noise injection with spike threshold indicated by green horizontal dashes. $\boldsymbol{b}$, Phase plot of $d V / d t$ versus $V$ of an action potential as it occurs in the soma. Note the biphasic nature of the spike. $c$, Expansion of the $d V / d t$ versus $V$ phase plot for somatic spikes illustrating spike threshold variance (range indicated by vertical dashed green lines). $\boldsymbol{d}$, In contrast to the soma, action potentials at the site of spike generation show a smooth onset and low threshold variance. Inset is as in $\boldsymbol{a}$. $\boldsymbol{e}$, Phase plot of $d V / d t$ versus $V$ for axonal spikes. $f$, Illustration of the lower variance in spike threshold in the axon initial segment (range indicated by vertical dashed green lines).

Injection of a noisy conductance into the soma of this model neuron resulted in the initiation of action potentials $\sim 35 \mu \mathrm{m}$ from the soma, followed by their backpropagation into the soma (data not shown). At the point of spike initiation, spikes rose smoothly from baseline (Fig. $8 d$ ), giving rise to a monophasic $d V / d t$ versus $V$ phase plot (Fig. 8e). In contrast, spikes in the soma had a kinky appearance (Fig. 8a), and exhibited a biphasic $d V / d t$ versus $V$ phase plot (Fig. $8 b$ ). Comparison of the variation in spike threshold revealed that it was higher in the soma than in the axon initial segment (Fig. 8, compare $c, f$ ). Quantifying these results revealed that they fell within the normal range of spike threshold variance and rate of rise for normal neurons (Fig. $2 e$; supplemental Fig. 14, available at www.jneurosci.org as supplemental material). We have examined a variety of models of cortical neurons, including one that is based on only a $3 \times$ increase in $g_{\mathrm{Na}}+$ density in the axon initial segment and a change in voltage sensitivity of $\mathrm{Na}^{+}$channels (supplemental Fig. 11, available at www.jneurosci.org as supplemental material) (Hoffman et al., 1997; Migliore et al., 1999; Poolos et al., 2002) and another based on recent measurements of the properties of $\mathrm{Na}^{+}$currents in the axon initial segments of layer 5 pyramidal cells (Kole et al., 2008) (supplemental Fig. 12, available at www.jneurosci.org as supplemental material). All of these HH models exhibited action potentials whose rate of rise at spike onset and apparent variability of spike threshold were similar to those exhibited by real layer 5 pyramidal cells (supplemental Fig. 14, available at www. jneurosci.org as supplemental material), as long as the action potentials naturally initiated within the axon initial segment and backpropagated into the soma.

\section{Discussion}

We demonstrate here that normal spike generation in cortical pyramidal cells, which results from the initiation of the action potential in the axon initial segment followed by backpropagation into the soma and dendrite (Stuart et al., 1997a; Palmer and Stuart, 2006; Shu et al., 2007b), is characterized by two features: a sharp rate of rise at onset and an apparent high level of somatic spike threshold variance. Using simple models, as well as full cortical neuronal models, we demonstrate that these properties are as expected from $\mathrm{HH}$ models, if spike propagation is taken into account.

\section{Functional implications of apparent high somatic spike threshold variability}

Variability in somatic spike threshold has been suggested to be an important factor in cortical processing, both limiting the reliability of information transfer as well as contributing to "coincidence" detection as a possible mechanism of neuronal function (Azouz and Gray, 1999, 2000, 2003; Wilent and Contreras, 2005). Two sources of spike threshold variability have been identified: variations in spike threshold caused by changes in the rate of membrane potential change $(d V / d t)$ approaching the action potential onset, and the history of action potential generation (Azouz and Gray, 1999, 2000; Henze and Buzsaki, 2001; Shu et 
al., 2003). However, these two variables are only able to explain $\sim 40-60 \%$ of somatic spike threshold variability. Our results indicate that a major factor contributing to somatic spike threshold variability is that the spikes are initiated at a distance, in the axon initial segment. We found that actual spike threshold variability at the point of spike initiation is significantly lower than previously appreciated from somatic recordings. This result indicates that variation in membrane potential between the axon initial segment and soma is an important source for apparent variability of somatic spike threshold, and that variation in actual spike threshold is limited and likely to contribute less to cortical processing than has been emphasized.

In addition, our results emphasize the importance of ionic and synaptic currents along the axon initial segment as being critical to determining spike timing and spike threshold variance. The axon initial segment is a unique structure containing a high density of transient and persistent $\mathrm{Na}^{+}$currents (Komada and Soriano, 2002; Astman et al., 2006; Inda et al., 2006; Kole et al., 2008), slowly inactivating $\mathrm{K}^{+}$currents (Kole et al., 2007; Shu et al., 2007a), and modulatory neurotransmitter receptors (Azmitia et al., 1996), and is selectively contacted by axoaxonic (chandelier) GABAergic interneurons (for review, see Howard et al., 2005). The unique electrophysiological and synaptic features of the AIS can result in significant variations in membrane potentials between this structure and the soma/dendrites, resulting in an apparent high level of spike threshold variance in the latter. These results emphasize the key role of the currents, synapses, and receptors in the AIS in the determination of the processing properties of cortical neurons, and by extension, to the operating principles of the cortex itself. One particularly interesting example is our demonstration of significant "remixing" of subthreshold frequencies and action potential timing with propagation through neuronal processes (Fig. 6). A well known property of filters is that they not only change the amplitude of a signal, but also its phase relationship, both in a frequency-dependent manner. This distance-dependent variation in phase relationship, which varies with frequency, will restrict spike-timing dependent plasticity for neurons experiencing the complicated patterns of synaptic barrage expected to occur in vivo, because the temporal relationship between membrane potential, distal dendritic synaptic inputs, and backpropagating action potentials may exhibit significant variation throughout different parts of the neuron. Phase variations can even result in action potentials occurring on the hyperpolarizing trough of membrane potential deviations in some regions of the model cortical neuron (Yu and McCormick, unpublished observations).

Recently, the validity of the Hodgkin-Huxley model for spike generation in cortical neurons was brought into question (Gutkin and Ermentrout, 2006; Naundorf et al., 2006). Single- and two-compartment models of nonpropagating spike generation in cortical neurons were unable to generate action potentials that simultaneously had the property of rapid rise of $V_{\mathrm{m}}$ at spike initiation and a high threshold membrane potential variance (Naundorf et al., 2006). Naundorf et al. (2006) suggested that $\mathrm{Na}^{+}$channel gating cooperativity, in which $\mathrm{Na}^{+}$channels open and close in unison, is responsible for these features of spike initiation in cortical pyramidal cells. However, our results reveal a more parsimonious explanation (McCormick et al., 2007). We demonstrate here that the initiation of action potentials in the axon initial segment, followed by the backpropagation of these spikes into the soma and dendrite, results in both the appearance of an unusually rapid rate of rise at the foot of the somatic spike, as well as an unusually high level of spike threshold variance. Both our simple and full $\mathrm{HH}$ models are able to replicate these properties and indeed are in reasonable agreement with results obtained with simultaneous somatic and axonal whole-cell recordings from layer 5 pyramidal cells.

One important parameter of models of cortical spike generation is the density and properties of the $\mathrm{Na}^{+}$conductance in the soma, dendrites, and axon. Immunocytochemical studies reveal a high density of $\mathrm{Na}^{+}$channels in the axon initial segment of cortical pyramidal cells (Komada and Soriano, 2002; Inda et al., 2006; Kole et al., 2008) as well as other cell types (Wollner and Catterall, 1986). Initial patch-clamp recordings from axon initial segments of pyramidal neurons suggested a $\mathrm{Na}^{+}$channel density that is only one to three times that of the soma (Colbert and Pan, 2002), although more recent studies have demonstrated that this low density may be an artifact of a tight association of $\mathrm{Na}^{+}$channels with the intra-axonal cytoskeleton, which limits the ability to draw $\mathrm{Na}^{+}$channels into the recording pipette during the patch procedure (Kole et al., 2008). Kole et al. (2008) demonstrate with $\mathrm{Na}^{+}$imaging, axonal patch-clamp recording before and after disruption of the actin cytoskeleton, ion replacement, and modeling that the density of $\mathrm{Na}^{+}$channels in the AIS of layer 5 pyramidal cells is $\sim 50 \times$ that of the soma and dendrites.

In our full neuron model, we adjusted the density of $g_{\mathrm{Na}}$ in our models such that the peak rate of rise of action potentials was comparable with that obtained in our axonal "bleb" recordings or in direct patch-clamp recordings of the axon initial segment (Kole et al., 2007). Using this approach, we found it satisfactory to use a density of $\mathrm{Na}^{+}$channels in the axon initial segment that was $\sim 10$-fold that of the soma. We found that the presence of a kink and increased variability in somatic spike initiation was robust over a wide range of axonal and somatic $\mathrm{Na}^{+}$channel densities (ratio of axonal to somatic densities from 3 to $15,000 \times$ ) and across different models of spike initiation, including one based on a low activation threshold for $\mathrm{Na}^{+}$channels in the axon initial segment (supplemental Figs. 11, 12, 14, available at www. jneurosci.org as supplemental material). Because the kink and increased spike threshold variability arises from the recording of action potentials distal to their site of generation, we found that every model that initiates spikes at a distance exhibited these basic properties. We conclude that the suggestion that $\mathrm{Na}^{+}$channels act cooperatively to generate rapidly initiating action potentials with high threshold variability (Naundorf et al., 2006) is unwarranted and counter to the properties of real cortical pyramidal cells.

Understanding the transformation of the ever-changing variations of membrane potential resulting from the complex synaptic barrages arriving in individual neurons into trains of action potentials and variations in synaptic release (Shu et al., 2006) is critical to understanding the basic operating principles of the neocortex. Future investigations will need to consider carefully the properties of the region of spike generation, the axon initial segment, and how the timing and properties of these axoninitiated action potentials interact with local and distal dendritic compartments as they propagate throughout the cell.

\section{References}

Anderson JS, Lampl I, Gillespie DC, Ferster D (2000) The contribution of noise to contrast invariance of orientation tuning in cat visual cortex. Science 290:1968-1972.

Astman N, Gutnick MJ, Fleidervish IA (2006) Persistent sodium current in layer 5 neocortical neurons is primarily generated in the proximal axon. J Neurosci 26:3465-3473.

Azmitia EC, Gannon PJ, Kheck NM, Whitaker-Azmitia PM (1996) Cellular 
localization of the 5-HT1A receptor in primate brain neurons and glial cells. Neuropsychopharmacology 14:35-46.

Azouz R, Gray CM (1999) Cellular mechanisms contributing to response variability of cortical neurons in vivo. J Neurosci 19:2209-2223.

Azouz R, Gray CM (2000) Dynamic spike threshold reveals a mechanism for synaptic coincidence detection in cortical neurons in vivo. Proc Natl Acad Sci U S A 97:8110-8115.

Azouz R, Gray CM (2003) Adaptive coincidence detection and dynamic gain control in visual cortical neurons in vivo. Neuron 37:513-523.

Black JA, Kocsis JD, Waxman SG (1990) Ion channel organization of the myelinated fiber. Trends Neurosci 13:48-54.

Colbert CM, Johnston D (1996) Axonal action-potential initiation and $\mathrm{Na}+$ channel densities in the soma and axon initial segment of subicular pyramidal neurons. J Neurosci 16:6676-6686.

Colbert CM, Pan E (2002) Ion channel properties underlying axonal action potential initiation in pyramidal neurons. Nat Neurosci 5:533-538.

Coombs JS, Curtis DR, Eccles JC (1957) The generation of impulses in motoneurones. J Physiol 139:232-249.

Destexhe A, Rudolph M, Fellous JM, Sejnowski TJ (2001) Fluctuating synaptic conductances recreate in vivo-like activity in neocortical neurons. Neuroscience 107:13-24.

Destexhe A, Rudolph M, Paré D (2003) The high-conductance state of neocortical neurons in vivo. Nat Rev Neurosci 4:739-751.

Fricker D, Verheugen JA, Miles R (1999) Cell-attached measurements of the firing threshold of rat hippocampal neurones. J Physiol 517:791-804.

Gutkin B, Ermentrout GB (2006) Neuroscience: spikes too kinky in the cortex? Nature 440:999-1000.

Henze DA, Buzsáki G (2001) Action potential threshold of hippocampal pyramidal cells in vivo is increased by recent spiking activity. Neuroscience 105:121-130.

Hines ML, Carnevale NT (1997) The NEURON simulation environment. Neural Comput 9:1179-1209.

Hodgkin AL, Huxley AF (1952) A quantitative description of membrane current and its application to conduction and excitation in nerve. J Physiol 117:500-544.

Hoffman DA, Magee JC, Colbert CM, Johnston D (1997) K+ channel regulation of signal propagation in dendrites of hippocampal pyramidal neurons. Nature 387:869-875.

Howard A, Tamas G, Soltesz I (2005) Lighting the chandelier: new vistas for axo-axonic cells. Trends Neurosci 28:310-316.

Inda MC, DeFelipe J, Muñoz A (2006) Voltage-gated ion channels in the axon initial segment of human cortical pyramidal cells and their relationship with chandelier cells. Proc Natl Acad Sci U S A 103:2920-2925.

Kole MH, Letzkus JJ, Stuart GJ (2007) Axon initial segment Kv1 channels control axonal action potential waveform and synaptic efficacy. Neuron 55:633-647.

Kole MH, Ilschner SU, Kampa BM, Williams SR, Ruben PC, Stuart GJ (2008) Action potential generation requires a high sodium channel density in the axon initial segment. Nat Neurosci 11:178-186.

Komada M, Soriano P (2002) [Beta]IV-spectrin regulates sodium channel clustering through ankyrin- $\mathrm{G}$ at axon initial segments and nodes of Ranvier. J Cell Biol 156:337-348.

Mainen ZF, Sejnowski TJ (1995) Reliability of spike timing in neocortical neurons. Science 268:1503-1506.

Mainen ZF, Sejnowski TJ (1996) Influence of dendritic structure on firing pattern in model neocortical neurons. Nature 382:363-366.

Mainen ZF, Joerges J, Huguenard JR, Sejnowski TJ (1995) A model of spike initiation in neocortical pyramidal neurons. Neuron 15:1427-1439.
McCormick DA, Huguenard JR (1992) A model of the electrophysiological properties of thalamocortical relay neurons. J Neurophysiol 68:1384-1400.

McCormick DA, Shu Y, Yu Y (2007) Neurophysiology: Hodgkin and Huxley model—still standing? Nature 445:E1-E2; discussion E2-E3.

Migliore M, Hoffman DA, Magee JC, Johnston D (1999) Role of an A-type $\mathrm{K}+$ conductance in the back-propagation of action potentials in the dendrites of hippocampal pyramidal neurons. J Comput Neurosci 7:5-15.

Naundorf B, Wolf F, Volgushev M (2006) Unique features of action potential initiation in cortical neurons. Nature 440:1060-1063.

Neher E (1992) Correction for liquid junction potentials in patch clamp experiments. Methods Enzymol 207:123-131.

Nowak LG, Sanchez-Vives MV, McCormick DA (1997) Influence of low and high frequency inputs on spike timing in visual cortical neurons. Cereb Cortex 7:487-501.

Palmer LM, Stuart GJ (2006) Site of action potential initiation in layer 5 pyramidal neurons. J Neurosci 26:1854-1863.

Paré D, Shink E, Gaudreau H, Destexhe A, Lang EJ (1998) Impact of spontaneous synaptic activity on the resting properties of cat neocortical pyramidal neurons In vivo. J Neurophysiol 79:1450-1460.

Poolos NP, Migliore M, Johnston D (2002) Pharmacological upregulation of h-channels reduces the excitability of pyramidal neuron dendrites. Nat Neurosci 5:767-774.

Rudolph M, Pelletier JG, Paré D, Destexhe A (2005) Characterization of synaptic conductances and integrative properties during electrically induced EEG-activated states in neocortical neurons in vivo. J Neurophysiol 94:2805-2821.

Shu Y, Hasenstaub A, Badoual M, Bal T, McCormick DA (2003) Barrages of synaptic activity control the gain and sensitivity of cortical neurons. J Neurosci 23:10388-10401.

Shu Y, Hasenstaub A, Duque A, Yu Y, McCormick DA (2006) Modulation of intracortical synaptic potentials by presynaptic somatic membrane potential. Nature 441:761-765.

Shu Y, Yu Y, Yang J, McCormick DA (2007a) Selective control of cortical axonal spikes by a slowly inactivating $\mathrm{K}+$ current. Proc Natl Acad Sci U S A 104:11453-11458.

Shu Y, Duque A, Yu Y, Haider B, McCormick DA (2007b) Properties of action-potential initiation in neocortical pyramidal cells: evidence from whole cell axon recordings. J Neurophysiol 97:746-760.

Stuart G, Schiller J, Sakmann B (1997a) Action potential initiation and propagation in rat neocortical pyramidal neurons. J Physiol 505:617-632.

Stuart G, Spruston N, Sakmann B, Häusser M (1997b) Action potential initiation and backpropagation in neurons of the mammalian CNS. Trends Neurosci 20:125-131.

Waxman SG (1995) Voltage-gated ion channels in axons: localization, function, and development. In: The axon. Structure, function and pathophysiology (Waxman SG, Kocsis JD, Stys PK, eds), pp 218-239. New York: Oxford UP.

Waxman SG, Ritchie JM (1993) Molecular dissection of the myelinated axon. Ann Neurol 33:121-136.

Wilent WB, Contreras D (2005) Stimulus-dependent changes in spike threshold enhance feature selectivity in rat barrel cortex neurons. J Neurosci 25:2983-2991.

Wollner DA, Catterall WA (1986) Localization of sodium channels in axon hillocks and initial segments of retinal ganglion cells. Proc Natl Acad Sci U S A 83:8424-8428. 